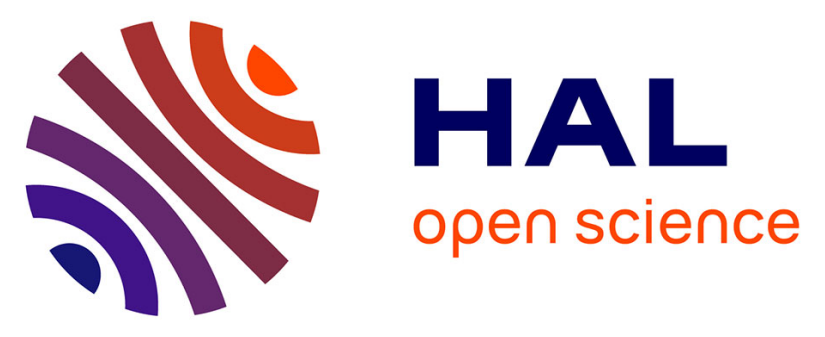

\title{
A modelling approach to explore the critical environmental parameters influencing the growth and establishment of the invasive seaweed Undaria pinnatifida in Europe
}

James T. Murphy, Mark P. Johnson, Frédérique Viard

\section{To cite this version:}

James T. Murphy, Mark P. Johnson, Frédérique Viard. A modelling approach to explore the critical environmental parameters influencing the growth and establishment of the invasive seaweed Undaria pinnatifida in Europe. Journal of Theoretical Biology, 2016, 396, pp.105-115. 10.1016/j.jtbi.2016.01.038 . hal-01297475

\section{HAL Id: hal-01297475 \\ https://hal.sorbonne-universite.fr/hal-01297475}

Submitted on 4 Apr 2016

HAL is a multi-disciplinary open access archive for the deposit and dissemination of scientific research documents, whether they are published or not. The documents may come from teaching and research institutions in France or abroad, or from public or private research centers.
L'archive ouverte pluridisciplinaire HAL, est destinée au dépôt et à la diffusion de documents scientifiques de niveau recherche, publiés ou non, émanant des établissements d'enseignement et de recherche français ou étrangers, des laboratoires publics ou privés. 
2 A modelling approach to explore the critical environmental parameters influencing the growth and establishment of the invasive seaweed Undaria pinnatifida in Europe

a'Sorbonne Universités, UPMC Univ Paris 6, CNRS, UMR 7144, Department « Adaptation \& Diversity in Marine Environment », Divco team, Station Biologique de Roscoff, Place Georges Teissier, 29680 Roscoff, France.

${ }^{\mathrm{b}}$ Marine Environment Research Group, Ryan Institute, National University of Ireland Galway, Galway, Ireland.

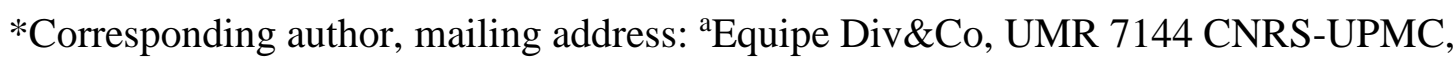

15 Station Biologique de Roscoff, Place Georges-Teissier CS 90074, 29688 Roscoff Cedex,

16 France. Phone: +33 2982956 57. Email: jmurphy@sb-roscoff.fr 


\section{Abstract:}

22 A key factor to determine the expansion dynamics and future distribution of non-native species is their physiological response to abiotic factors and their changes over time. For this study we developed a spatially explicit, agent-based model of population growth to represent the complex population dynamics of invasive marine macroalgae with heteromorphic biphasic life cycles. The model framework represents this complex life cycle by treating the individual developmental stages (gametophytes/sporophytes) as autonomous agents with unique behaviour/growth parameters. It was parameterised to represent a well-documented invasive algal species, the Asian kelp Undaria pinnatifida, and validated against field results from an in situ population in Brittany, France, showing good quantitative agreement in terms of seasonal changes in abundance/recruitment and growth dynamics. It was then used to explore how local environmental parameters (light availability, temperature and day length) affect the population dynamics of the individual developmental stages and the overall population growth. This type of modelling approach represents a promising tool for understanding the population dynamics of macroalgae from the bottom-up in terms of the individual interactions between the independent life history stages (both microscopic and macroscopic). It can be used to trace back the behaviour of the population as a whole to the underlying physiological and environmental processes impacting each developmental stage and give insights into the roles these play in invasion success.

\section{Keywords:}

Macroalgae; agent-based model; individual-based model; invasive species; seaweed; kelp; 


\section{Introduction:}

The introduction and establishment of non-native plant and animal species can have a broad range of impacts on native species and community structure as well as economic consequences through the disruption of ecosystem services (Simberloff et al., 2013; Vilà et al., 2009). However, it is often difficult to predict the actual (and future) invasive behaviour under changing environmental conditions, since it is seldom possible to determine the source of an introduction with certainty, especially in marine environments (Rius et al., 2015). A further level of complexity comes from the fact that the response of introduced species to environmental factors may differ between the native and introduced ranges, as a consequence of trait plasticity (Davidson et al., 2011). A recent study of plant invaders pointed out an increased physiological tolerance of successful introduced species (Higgins and Richardson, 2014). Niche shift may thus be more common than previously assumed, which may complicate ecological-niche modelling efforts (Parravicini et al., 2015).

Seaweeds account for $20-29 \%$ of all non-native marine species in Europe and they are an important concern because of their role as primary producers in coastal ecosystems (Engelen et al., 2015; Schaffelke and Hewitt Chad, 2007; Schaffelke et al., 2006). One example of a notable invasive species on a global scale is the brown kelp Undaria pinnatifida (Harvey) Suringar, 1873 (Phaeophyceae: Laminariales). This has traditionally been cultivated in its native range of eastern Asia, including Japan, Korea and China (Ohno and Matsuoka, 1993; Shao-jun and Chao-yuan, 1996). However, in recent decades it has arisen as an invasive threat in Europe, North America and New Zealand among other places, due to human-mediated transport (Castric-Fey et al., 1993; Fletcher and Farrell, 1998; Floc'h et al., 1991; Grulois et al., 2011; Hay and Luckens, 1987; Silva et al., 2002; Voisin et al., 2005).

The order Laminariales (kelp) is characterised by a heteromorphic life history that consists of two distinct phases: a haploid gametophyte stage and a diploid sporophyte stage 
71 (see Fig. 1) (Bessho and Iwasa, 2010; Clayton, 1988). Each stage has specific environmental requirements for optimal growth and development, in particular with respect to water temperature, light intensity and photoperiod (daily light:dark ratio) (Floc'h et al., 1991).

One key outcome of biological invasion studies has been to point out the role played by match-mismatch between the physiological requirements of the introduced species and the local environmental conditions. It is important to define the conditions under which introduced species expand (locally or spatially) in order to predict their fate. However, in many marine species, it is difficult to make predictions due to their complex life cycle and substantial variation in physiological traits. The purpose of this study was thus to propose a modelling approach that takes into account both the individual stages of the life cycle and their specific environmental requirements, when modelling the overall population dynamics.

An agent-based (or individual-based) modelling approach was chosen in order to be able to integrate data on the basic physiological properties of $U$. pinnatifida individuals into an overall model of population growth. This allows the individual life history stages (gametophytes/sporophytes) to be represented as autonomous agents and their behaviour/interactions to be explicitly described. This so-called bottom-up approach means that the emergent dynamics, at the population level, can be traced back to the individual components (Denny and Benedetti-Cecchi, 2012; Grimm and Railsback, 2005).

The main challenge in building an agent-based model of a complex biological system such as this is the ability to parameterise it. For this reason, a thorough review of the literature was first carried out in order to gather empirical data on the basic responses of the individual life stages of $U$. pinnatifida from a mechanistic point of view. We then tested the model for accuracy and robustness by comparing it with an empirical data set from a natural population in Brittany, France (Voisin, 2007). This step was critical as phenotypic plasticity is often assumed to be an important characteristic of invasive species. Finally, we used the 
model to explore how some of the critical environmental parameters influence the population dynamics of the test species.

This type of low-level insight can help us to understand the role that climatic conditions play in the invasion dynamics of $U$. pinnatifida and other invasive macroalgae. The aim of this research was to develop a framework for exploring how direct and indirect effects on the life cycle and individual life history stages of macroalgae determine their population dynamics and invasive potential. This could enable better predictions about the potential future spread and range distribution of invasive seaweeds under changing climatic conditions. Furthermore, the agent-based approach means that heterogeneities in local environmental conditions, and between individual life history stages, can be explicitly accounted for in order to be able to predict the potential emergent dynamics at the population level.

\section{The Model}

The model was built upon a generic agent-based framework called CoastGEN, built in the $\mathrm{C}^{++}$programming language, which has been developed to simulate populations of biological entities in a discrete two-dimensional environment (Murphy and Johnson, 2015). The advantages of this framework are that it is fully parallelisable (using domain decomposition and the Message Passing Interface) to take advantage of distributed computing architectures and it represents a robust and adaptable tool to simulate spatially and temporally heterogeneous phenomena (Gropp et al., 1996).

A detailed individual-based model of the life history of U. pinnatifida (including distinct microscopic gametophyte and macroscopic sporophyte stages) was built upon this basic framework for the purposes of this study. The input parameters used for the simulations in this paper are summarised in Table 1. Additional stochasticity is introduced into the model 
121 by adding random individual variability when initialising each agent's parameters, using the

122 Mersenne twister pseudo-random number generator (Matsumoto and Nishimura, 1998).

123

\section{2.1. The environment}

The coastal environment is represented as a discrete, two-dimensional grid with each grid element corresponding to $0.25 \mathrm{~m}^{2}$ of surface area and periodic boundary conditions. This allows for heterogeneity in the environmental conditions and spatial distribution of organisms, as opposed to assuming a completely homogeneous, mixed environment. The maximum number of agents (gametophytes/sporophytes) that may occupy a lattice position can be specified by the user. For the purposes of the simulations in this paper, this value was set to $10^{4}$, which was selected in order to avoid space limitations affecting the growth curves over the timescales involved in the simulations in this paper. To investigate the role of space limitations and competition in the natural environment, a more detailed model of frond structure and competition for light will need to be incorporated in future versions.

The availability of light in the water column is a function of the light attenuation coefficient for photosynthetically available radiation (K $\mathrm{K}_{\mathrm{dPAR}}$ ) (Saulquin et al., 2013). This represents light attenuation in the water column due to backscattering of light caused by suspended matter and absorption by dissolved organic matter. Estimates of surface irradiance together with the $\mathrm{K}_{\mathrm{dPAR}}$ are used to calculate the residual energy (I) available for

140 photosynthesis at a given depth:

$$
I=E(z)=E(0) e^{-z K_{d P A R}}
$$

where $z$ is depth $(\mathrm{m}), E(0)$ is surface irradiance, and $E(z)$ is the irradiance energy

143 available for photosynthesis at depth $z$. The average depth for the test simulations in this

144 paper was set to $1.0 \mathrm{~m}$. This was chosen in order to match the conditions from field surveys 
145 of a natural population in Brest harbour which involved installing sampling panels that were

146 suspended approximately a metre below the floating pontoons (Voisin, 2007).

At lower depths, growth becomes inhibited due to light limitation and peak recruitment is expected to decrease as a function of depth. This is why floating pontoons

149 represent appropriate substrates for early colonisation by $U$. pinnatifida since they are maintained at a constant depth relative to the surface. Future work will involve more detailed analyses of the effects of depth and light attenuation on the growth of the various life history stages. However, for the purposes of this study, the depth was maintained at a constant value in order to represent optimal conditions for growth.

\subsection{Gametophyte agents}

Gametophytes are the microscopic haploid stages of the $U$. pinnatifida life cycle (see

Fig. 1). In the model, their relative daily growth rate is calculated as a function of the water temperature, solar radiation, and number of day light hours. Experimental data is available in the literature for $U$. pinnatifida gametophytes growing under different temperature regimes

160 (Morita et al., 2003a). To represent the effect of temperature on growth, a thermal performance curve (Stevenson et al., 1985) was fitted to this data (Fig. 2a, $\mathrm{R}^{2}>0.99$ ):

$$
R G R_{-} G_{T}=S\left[\frac{1}{\left(1+K_{1} e^{-K_{2}}\left(T_{w}-C T_{\min }\right)\right.}\right] \times\left[1-e^{K_{3}\left(T_{w}-C T_{\max }\right)}\right]
$$
water temperature $K_{1}, K_{2}$ and $K_{3}$ are constants, $C T_{\min }$ and $C T_{\max }$ are the lower and upper critical temperature limits respectively, and $S$ is a scaling factor.

Furthermore, it has been shown in studies that the growth rate of gametophytes is sensitive to changes in both solar irradiance and day length (Choi et al., 2005). This data set was used to generate a photosynthesis-irradiance curve by fitting the hyperbolic equation of 
Jassby and Platt (1976) to empirical measurements of $U$. pinnatifida gametophytes by Choi et al. (2005) (Fig. 2b, $\mathrm{R}^{2}>0.99$ ):

$$
R E G_{-} G_{I}=P_{\max } \cdot\left(1-\exp \left[-\alpha \cdot \frac{I-I_{c}}{P_{\max }}\right]\right)
$$

170

171

$$
\begin{aligned}
& \alpha=0.029 d-0.198 \\
& P_{\max }=0.292 e^{0.11 d}
\end{aligned}
$$

By incorporating these equations into the model it allows us to estimate the relative daily growth rate of the gametophyte agents $\left(R G R \_G\right)$ at any point in time as a function of the current temperature, irradiance and day length conditions:

$$
R G R \_G=R G R \_G_{T} \times R E G_{-} G_{I}
$$




\subsection{Gametogenesis}

The maturation and production of gametes (or gametogenesis) by gametophytes, and

the subsequent fertilisation to form new sporophytes are important processes influenced by external environmental cues. Experimental tests have demonstrated that there is a relationship

192 between day length/water temperature and the maturation of female gametophytes of $U$.

193 pinnatifida (Choi et al., 2005; Morita et al., 2003a). over the range $10-25^{\circ} \mathrm{C}$ was explored by Morita et al. (2003a). They demonstrated a peak in fertility at $10-15^{\circ} \mathrm{C}$ with an approximately exponential decrease in fertility above that. A simple logistic function was chosen to represent this as it showed a good fit against the data over the temperature range explored (Fig. 2c, $\mathrm{R}^{2}=0.97$ ):

$$
R F_{T}=1-\left[\frac{1}{\left(1+e^{-k\left(t-t_{0}\right)}\right)}\right]
$$

where $R F_{T}$ is the relative fertility of the gametophytes in response to temperature, $k$ is the steepness of the curve, $t$ is the current water temperature, and $t_{0}$ is the temperature at the midpoint of the sigmoid.

The fertility of female gametophytes was also recorded by Choi et al. (2005) under $\left(\mathrm{R}^{2}>0.99\right)$ in order to represent the effect of day length on the relative fertility $\left(R F_{D L}\right)$ of the gametophyte agents (Fig. 2d). This curve was chosen because of its relative simplicity and flexibility (for example, it does not require any prior assumptions about symmetry in the data).

\subsection{Sporophyte agents}

Sporophyte agents are modelled from their initial microscopic cellular scale up to an eventual size of 1-3 metres (frond length), with growth represented as the relative daily 
212 increase in the total length of the frond structure. This represents a particular modelling

213 challenge due to the range of scales involved. Therefore, it was necessary to model the

214 relative growth rate as a function of the length of the sporophyte. Studies from the literature

215 were used to calculate the growth rate of sporophytes in different size classes (from

216 microscopic sporophytes in culture to mature sporophytes $79 \mathrm{~cm}$ in length) (Choi et al., 2007;

217 Pang and Lüning, 2004; Shao-jun and Chao-yuan, 1996). A power law functional relationship

218 between the relative growth rate and the length of the sporophyte was estimated by fitting to

219 this data (Fig. 3a, $\left.\mathrm{R}^{2}=0.97\right)$ :

$$
R G R_{-} S_{\text {base }}=3.615 l^{-0.407}
$$

where $l$ is the length of the sporophyte. This equation is used to calculate a baseline relative growth rate for sporophyte agents (RGR_S $S_{\text {base }}$ ) under “default” environmental conditions (irradiance $=40 \mu \mathrm{mol} \mathrm{m} \mathrm{m}^{-2}$, temperature $=15^{\circ} \mathrm{C}$ and day light (DL) hours $=12$ ). Furthermore, to account for the change in photosynthetic efficiency with increasing 224 frond length (i.e. due to increasing thallus complexity/density and the proportion of 225 differentiated cell types) the input parameters for the photosynthesis-irradiance curve of Jassby \& Platt (Eq. 3) are expressed as functions of sporophyte length (Eq. 8-10). These functions were derived by fitting to data from Campbell et al. (1999) on macroscopic sporophytes and Choi et al. (2005) on microscopic gametophytes $\left(\mathrm{R}^{2}>0.99\right.$ for all three curves).

$$
\begin{gathered}
P_{\max }=0.4 \ln (l)-0.596 \\
\alpha=0.5 l^{-0.328} \\
I_{c}=2.5 \ln (l)-19.92
\end{gathered}
$$

To estimate the initial photosynthetic efficiency of microscopic sporophytes (i.e. immediately following fertilisation when the proportion of differentiated cell types is still 
relatively good estimator of photosynthetic efficiency for the purposes of this model since the dry weight to fresh weight ratio of microscopic gametophytes and sporophytes would be expected to be similar due to the lack of differentiated cell types. The availability of equivalent data on cultured sporophytes would be preferable however.

Data from Pang and Lüning (2004) was used to characterise the effect of day length on the growth rate of sporophytes. They measured the time in weeks to maturity for sporophytes grown under different day length regimes and this was used to estimate the relative differences in growth rates. A hyperbolic curve (see Eq. 3) was then fitted to this data to predict the relative effect of day length on the growth rate (REG_S $\left.S_{D L}\right)$ (Fig. 3b, $\mathrm{R}^{2}>0.99$ ).

For temperature, a thermal performance curve was fitted to experimental data on sporophytes grown in water temperatures between $5-20^{\circ} \mathrm{C}$ by Morita et al. (2003b), using the same approach described for the gametophyte agents above (see eq. 2). Figure 3c shows the results of fitting the curve to Morita's data through least squares regression $\left(\mathrm{R}^{2}=0.99\right)$ in order to represent the relative effect of temperature on the growth rate $\left(R E G_{-} S_{T}\right)$. Finally, Fig. 3d shows an example of the photosynthesis-irradiance curve $\left(R E G \_S_{I}\right)$ for an $U$. pinnatifida sporophyte as calculated directly by Campbell et al. (1999).

The relative daily growth rate of each sporophyte agent $\left(R G R \_S\right)$ is thus a function of 250 the baseline growth rate and the relative effects of temperature, light and day length:

$$
R G R \_S=R G R \_S_{\text {base }} \times R E G \_S_{T} \times R E G \_S_{I} \times R E G \_S_{D L}
$$

In order to test the growth algorithm described above, some initial validation tests were carried out on the predicted growth rates for sporophytes of different lengths versus observations from the literature. For example, in cultivation experiments (irradiance $=100$ $\mu \mathrm{mol} \mathrm{m} \mathrm{m}^{-2} \mathrm{~s}^{-1}$, temp $=15^{\circ} \mathrm{C}, \mathrm{DL}=12 \mathrm{~h}$ ), Pang \& Luning (2004) recorded average growth rates 
recruits (length unspecified). Under similar conditions, the model predicts growth rates of recorded a relative growth rate (frond length) of $7.2 \%$ per day among a population of sporophytes with an average length of $79.06 \mathrm{~cm}$. This compares to a model predicted growth rate of 6.9\% (79 cm long, assuming light-saturated conditions).

Sporophytes agents die away naturally after reaching maturity and releasing all of their spores. However, the premature loss of sporophytes may also occur through potential random events (e.g. storms, grazers) which result in detachment/death. In fact, field studies in Brest harbour, France, have indicated that as much as $70 \%$ of all sporophyte recruits do not survive past their first month (Voisin, 2007). To account for this, an age to mortality curve (Weibull function) was calculated and fitted to the data from Brest harbour to determine the probability of premature death as a function of the age of the sporophyte (Fig. 4a).

\subsection{Spore Release}

Mature sporophytes are characterised by a distinct sporophyll structure at the base of their stipe in which the spores are formed. The mean size at maturity calculated for a population in Brest harbour, France was $32.66 \mathrm{~cm}$ (Voisin, 2007). This is used in the model to determine the mean minimum size at which spore release can occur. The release of spores by mature sporophytes is thought to be a temperature-dependent event (Saito, 1975). Suto (1952) recorded the average (10-day) sea water temperatures and the presence/absence of shedding among $U$. pinnatifida sporophytes in Japan (Suto, 1952). We used their original data to plot the frequency of spore release versus temperature and fitted a logistic function to this (Fig. 4b, $\mathrm{R}^{2}>0.99$ ).

For the test simulations in this paper, the mean spore release rate per individual sporophyte agent was set to $2.0 \times 10^{7}$ spores hour ${ }^{-1}$ and total spore production in a season is 
$28210^{10}$ spores sporophyte ${ }^{-1}$. This is within the range of estimates for the rate of spore release $283\left(1.0 \times 10^{7}-1.4 \times 10^{8}\right.$ spores $\left.^{-1}\right)$ and the total spore production $\left(>10^{9}\right)$ for $U$.pinnatifida from 284 the literature (Schaffelke et al., 2005; Suto, 1950). Once released, they are represented as 285 simple particles subject to a discretised implementation of Fick's First Law of diffusion for 286 dispersal across a lattice environment (Ginovart et al., 2002). Water currents are not explicitly 287 simulated, but in terms of local population dynamics a simple diffusion algorithm is thought to be sufficient due to the short lifespan of spore particles in the water column (Thiébaut et al., 1998).

Experimental studies have shown that $U$. pinnatifida spores can lose their fixing ability within hours of release and stop swimming within 3 days (Forrest et al., 2000; Suto, 1950). Therefore, they were assigned a relatively short half-life of 24 hours in the simulations. A gametophyte agent is formed when a spore comes into contact with a suitable substrate for attachment. In the model, this process is represented as a simple stochastic process where the probability of recruitment of new gametophytes ( $\left.\mathrm{P}_{\text {recruit }}\right)$ is a function of the number of spores occupying the lattice position $\mathrm{ij}\left(\mathrm{s}_{\mathrm{ij}}\right)$ at that point in time and a user-defined probability of attachment/germination on the substrate ( $\left.\mathrm{A}_{\text {substr }}\right)$ :

$$
P_{\text {recruit }}=A_{\text {substr }} S_{i j}
$$

\section{Results \& Discussion:}

\subsection{Model validation}

Simulations were carried out using environmental parameters (light, temperature and day length) representative of Brest harbour, France, in order to validate the model against real-world data collected by researchers at the Station Biologique de Roscoff, France. Surface water temperature data for the port of Brest (2003-06) were obtained from a SOMLIT 
306 (Service d’Observation en Milieu Littoral, INSU-CNRS, Brest, http://somlit-db.epoc.u307 bordeaux1.fr) buoy situated a few hundred metres from the marina (Voisin, 2007). 308 Meanwhile, sample mean global solar irradiance data for the region were obtained using the 309 CalSol online application (Institut National de L’Energie Solaire, CEA-CNRS).

$310 \quad$ Figure 5 shows model predictions for the overall sporophyte population growth of an 311 U. pinnatifida invasion in a harbour setting (for raw data, see Table 1, (Murphy et al., 312 (submitted))). The model displays an annual pattern of growth and decay characteristic of $U$. 313 pinnatifida populations in nature, in response to seasonal variations in light and temperature 314 levels. For validation purposes, this was compared to real-world field results from the port of 315 Brest in France during the 2005/06 growing season (Voisin, 2007): During this field 316 experiment, 64 aluminium panels were set-up one metre below the surface, a depth optimal 317 for the recruitment of the study species, and the settlement and length of each individual was recorded every month.

The raw data was first normalised to express the monthly abundance/recruitment values for the sporophytes relative to their peak annual abundance/recruitment respectively 321 (see Tables 2-3, (Murphy et al., (submitted))). This means that all monthly abundance values for a growing season (Aug-July) were expressed relative to the peak abundance in that year (usually in April). This was done in order to avoid bias in the results due to differences in population size and to focus on the relative seasonal variation in abundance/recruitment due to environmental effects.

The model results and field data were then plotted against each other in terms of overall abundance data and monthly recruitment rates (Fig. 6a \& b). The $\mathrm{R}^{2}$ values were 0.84 and 0.85 when comparing the model predictions and the real-world measurements for total abundance and monthly recruitment respectively over the course of the 12 months. Some variation from the real-world results is to be expected since factors such as competition and 
self-shading were not taken into account. Future work will involve extending the base model to incorporate intra- and inter-specific competition for light/space. cm in length) for Brest harbour compared with the model predictions. The model matches closely the seasonal pattern of growth observed in the real-world populations. The one exception is in November when the model over-predicts the rate of recruitment. Possible explanations for this include seasonal changes in the turbidity of the water affecting the growth of young sporophytes or increased mortality due to winter storm activity that year. also compared with field records from Brest (Fig. 7). There is good quantitative agreement between the model predictions and field measurements for life expectancy, age to maturity and duration of the mature phase respectively. This indicates that the physiological responses to environmental factors of the local population of $U$. pinnatifida match closely with predictions based on studies of individuals in its native range of eastern Asia. Voisin (2007) also investigated the important relationship between water temperature and the recruitment of sporophytes. Previous studies in California, USA, had identified recruitment pulses in $U$. pinnatifida populations associated with drops in ocean temperature 2 months prior to the recruitment (Thornber et al., 2004). Therefore, to investigate if the model reproduced this pattern the predicted rate of recruitment was plotted against the water temperature two months prior, and compared with similar field results from Brest. As can be seen in Figure 8, there is good overlap between model predictions and the real-world data (for raw data, see Table 4, (Murphy et al., (submitted))). They both show increased recruitment at lower temperatures, which agrees with data from the literature indicating significantly higher recruitment of sporophytes at temperatures below $15^{\circ} \mathrm{C}$ (Thornber et al., 2004; Voisin, 2007). 
It must be noted that apart from the use of a scaling factor, no attempt to fit the model parameters to the Brest population was made. The model input parameters were solely based on experimental records from various studies in the literature often involving geographically disparate populations of $U$. pinnatifida in their native range. Interestingly, the fact that the Brest population behaves similarly to the model predictions may indicate that relatively limited phenotypic adaptation has occurred in the local Brittany populations as compared to its native range, meaning that this species may be pre-adapted to a large set of environmental conditions, for the factors considered here. In this case, abiotic factors seem to be the dominant factor in influencing the local population dynamics. However, since U pinnatifida is a recent introduction to Brittany, there is the possibility that future adaptation to the new environment may play an important role in determining its continued spread in the region.

\subsection{Response to environmental parameters}

The next step was to explore the underlying system dynamics and critical parameters that contribute to the observed patterns of growth predicted by the model. To achieve this, the responses of the various developmental stages of $U$. pinnatifida to three key environmental parameters (light, temperature, and day length) were investigated using the model. Figures 911 represent the raw simulation output expressed in terms of these three environmental variables. All the plots come from an identical simulation run over the course of 56 months in order to exclude any variation due to differences in the initial conditions. By dissecting the model output like this, it is possible to gain insights into the underlying mechanisms for the observed patterns of population growth.

Figure 9 plots the relationship between water temperature and the growth/fertility of of the life cycle, the growth rate is moderately positively correlated with water temperature 
(Fig. 9a-b, $\mathrm{R}^{2}=0.65 \& 0.7$ respectively). However, temperature does not appear to play an important role in influencing gametophyte fertility, with a minor negative correlation predicted (Fig. 9c, $\mathrm{R}^{2}=0.4$ ). This is because the water temperature in Brest harbour rarely exceeds a value that would be expected to inhibit the maturation of gametophytes $\left(>21^{\circ} \mathrm{C}\right)$. However, this may play a greater role in influencing the population dynamics under scenarios of increasing sea water temperatures in the study area (Brittany) in the future (Gallon et al., 2014). Finally, spore release by mature sporophytes primarily occurs at higher water temperatures $>10^{\circ} \mathrm{C}$ (Fig. 9d). This agrees with field studies from the literature which suggested a critical minimum temperature value for spore release of approximately $12-14^{\circ} \mathrm{C}$ (Saito, 1975; Suto, 1952).

In the case of day light hours and solar radiation, these also play a key role in influencing the population dynamics of $U$. pinnatifida (Fig. $10 \&$ 11). The model results indicate a positive correlation between day light hours/solar radiation and the growth rate of gametophytes (Fig. 10a \& 11a: $R^{2}=0.82 \& 0.74$ respectively). Similarly, for sporophytes, there is a moderate positive correlation (Fig. $10 \mathrm{~b} \& 11 \mathrm{~b}: \mathrm{R}^{2}=0.6 \& 0.62$ respectively). In contrast, the fertility of gametophytes is negatively correlated with day length and light availability (Fig. $10 c \& 11 c: \mathrm{R}^{2}=0.87 \& 0.77$ respectively). These results suggest that gametogenesis and new sporophyte formation is adapted to occur during the shorter days of winter. Conversely, there is no clear relationship between spore release and either day length or solar radiation $\left(\mathrm{R}^{2}<0.1\right.$, Figs. $\left.10 \mathrm{~d} \& 11 \mathrm{~d}\right)$. This is because the model does not assume any relationship between these variables and spore release as there is no clear data from the literature of a direct causal relationship. history stages (particularly gametophyte fertility, gametophyte growth rates and sporophyte 404 growth rates) in response to the environmental parameters is an important consideration when 
attempting to explain the patterns of growth observed in populations of $U$. pinnatifida in the field. It is necessary to take into account these complex interactions in order to build up an accurate view of the invasion dynamics but this is often overlooked in population studies that focus on the macroscopic stages of the life cycle alone. Furthermore, these types of interactions are common in other species of macroalgae that exhibit dimorphic life cycles.

410 Therefore, a modelling approach which explicitly takes into account the differing responses 411 of the individual life stages may be a useful tool for understanding the complex non-linear dynamics of macroalgal populations in general.

The results in this paper illustrate how the characteristic seasonal growth patterns

414 observed among populations of $U$. pinnatifida in Brest harbour are dictated by the differing 415 responses of the individual life history stages to environmental parameters: Gametophytes mature and reproduce to form new sporophytes during the shorter days of the winter when

417 light availability is lowest. They reach maturity in the spring and release their spores in the early summer when light availability is at its peak, before dying out gradually during the

419 spring and summer months. The population dynamics of the gametophyte stages in field 420 populations are less well understood. However, the model predicts that the density of gametophytes is expected to peak in the summer months but there is a delay before maturity is reached during the autumn when appropriate conditions (day length/solar irradiance) are 423 present.

The individual-based modelling approach allows us to make quantitative predictions 425 about the temporal and spatial dynamics affecting this seasonal schedule using basic 426 physiological data on the species. It has been suggested that the heteromorphic life cycle of macroalgal species such as $U$. pinnatifida may have evolved in response to seasonal changes in temperate climates (Bessho and Iwasa, 2009). Therefore, it is important to take into 
account the ecophysiological responses of the individual life history stages when attempting to make predictions about the responses of the population as a whole.

entities and to connect the local interactions at the individual-scale to the overall population dynamics. A greater understanding of the mechanistic basis for these responses could allow predictions about how populations will respond to changing environmental conditions in the future (such as increasing sea water temperatures) and the potential for future range expansion in Europe and other regions of the world. There is an extra computational burden associated with the IBM approach and it is more dependent on empirical knowledge compared to simpler state variable modelling approaches. However, by using appropriate aggregation of parameters in order to simplify the model, and cognizant of its limitations, it can be a useful approach to supplement, rather than supplant, existing theoretical approaches, such as metapopulation models, when local interactions play an important role (McCauley et al., 1993).

In addition, the IBM approach provides a framework to understand how processes at the individual level and local interactions affect invasion success. It allows spatial heterogeneity (or patches) to be generated both "internally", by the interactions and movements of the organisms, as well as imposed "externally" (for example, by specifying the structure of a harbour with different substrates, currents etc.). This allows the effects of local rules, for migration or diffusion between or among patches, on population dynamics to be assessed. It also allows one to differentiate the responses of the gametophyte and sporophyte stages and to isolate the key factors that limit/promote the population growth/fitness under a given set of environmental conditions. This can help to inform strategies for control/eradication of invasive populations by identifying susceptible stages in the life cycle 
453 schedule and the timing of intervention, or to assess the risk for spread and establishment of 454 the species in a region.

455

456

\section{Conclusions \& Future Work:}

We present a novel agent-based modelling framework for simulating marine macroalgal species taking into account their complex biphasic life histories. Initial validation results indicate that the model can accurately predict the growth dynamics of an in situ population of invasive seaweed (U. pinnatifida, in Brest harbour, France) and give insights into the underlying population dynamics that contributed to its establishment. This type of modelling approach represents a promising tool for understanding the effects of changing environmental conditions (both temporal: e.g. climate change; and spatial: e.g. by range expansion) on the growth dynamics and distribution of invasive seaweed species. Moreover, through building a mechanistic representation of the important life history stages of the species, and modelling their basic interactions at an individual level, it is possible to build up a more complete understanding of the underlying dynamics driving their spread and establishment. This can have applications in terms of informing control strategies for invasive populations and risk assessment for the potential spread and establishment of non-native species.

Future work will involve extending the model to represent more complex spatial and temporal patterns of invasion in order to be able to explore the impact of these factors on invasion dynamics. A detailed competition model will be incorporated to represent the

474 potential interactions between different algal species and local ecosystem dynamics. This 475 individual-based approach could also enable investigations into more long term processes such as the role of phenotypic/genotypic variation and evolutionary selective pressures on invasion dynamics. 
Acknowledgements:

480 This research is supported by an Irish Research Council ELEVATE international career development fellowship, co-funded by Marie Curie Actions under the European Union’s

Seventh Framework Programme. The field data presented here, which were collected in

Brest, were obtained as part of the PhD thesis of Marie Voisin who benefitted from a Ph.D.

fellowship (“Renouvellement des Compétences” Program) from the Region Bretagne. MV

485

and FV are thankful to the many people from the Department AD2M of the Station

Biologique de Roscoff who provided help for the surveys carried out in the field.

\section{References:}

489

490

491

492

493

494

495

496

497

498

499

500

501

502

503

504

505

506

507

508

509

510

511

512

513

514

515

Bessho, K., and Iwasa, Y., 2009. Heteromorphic and isomorphic alternations of generations in macroalgae as adaptations to a seasonal environment. Evolutionary Ecology Research 11, 691-711.

Bessho, K., and Iwasa, Y., 2010. Optimal seasonal schedules and the relative dominance of heteromorphic and isomorphic life cycles in macroalgae. Journal of Theoretical Biology 267, 201-212.

Campbell, S.J., Bité, J.S., and Burridge, T.R., Seasonal Patterns in the Photosynthetic Capacity, Tissue Pigment and Nutrient Content of Different Developmental Stages of Undaria pinnatifida (Phaeophyta: Laminariales) in Port Phillip Bay, South-Eastern Australia, Botanica Marina, Vol. 42. 1999, pp. 231.

Castric-Fey, A., Girard, A., and L'Hardy-Halos, M.T., The Distribution of Undaria pinnatifida (Phaeophyceae, Laminariales) on the Coast of St. Malo (Brittany, France), Botanica Marina, Vol. 36. 1993, pp. 351.

Choi, H., Kim, Y., Lee, S., and Nam, K., 2007. Growth and reproductive patterns of Undaria pinnatifida sporophytes in a cultivation farm in Busan, Korea. Journal of Applied Phycology 19, 131-138.

Choi, H., Kim, Y., Lee, S., Park, E., and Nam, K., 2005. Effects of daylength, irradiance and settlement density on the growth and reproduction of Undaria pinnatifida gametophytes. Journal of Applied Phycology 17, 423-430.

Clayton, M.N., Evolution and Life Histories of Brown Algae, Botanica Marina, Vol. 31. 1988, pp. 379.

Davidson, A.M., Jennions, M., and Nicotra, A.B., 2011. Do invasive species show higher phenotypic plasticity than native species and, if so, is it adaptive? A meta-analysis. Ecology Letters 14, 419-431.

Denny, M., and Benedetti-Cecchi, L., 2012. Scaling Up in Ecology: Mechanistic Approaches. Annual Review of Ecology, Evolution, and Systematics 43, 1-22. 
Engelen, A.H., Serebryakova, A., Ang, P., Britton-Simmons, K., Mineur, F., Pedersen, M.F., Arenas, F., Fernández, C., Steen, H., Svenson, R., Pavia, H., Toth, G., Viard, F., and Santos, R., Circumglobal invasion by the brown seaweed Sargassum muticum, Oceanography and Marine Biology: An Annual Review, Vol. 53. Taylor \& Francis 2015, pp. 81-126.

Fletcher, R.L., and Farrell, P., 1998. Introduced brown algae in the North East Atlantic, with particular respect to Undaria pinnatifida (Harvey) suringar. Helgoländer Meeresuntersuchungen 52, 259-275.

Floc'h, J.Y., Pajot, R., and Wallentinus, I., 1991. The Japanese brown alga Undaria pinnatifida on the coast of France and its possible establishment in European waters. Journal du Conseil: ICES Journal of Marine Science 47, 379-390.

Forrest, B.M., Brown, S.N., Taylor, M.D., Hurd, C.L., and Hay, C.H., 2000. The role of natural dispersal mechanisms in the spread of Undaria pinnatifida (Laminariales, Phaeophyceae). Phycologia 39, 547-553.

Gallon, R.K., Robuchon, M., Leroy, B., Le Gall, L., Valero, M., and Feunteun, E., 2014. Twenty years of observed and predicted changes in subtidal red seaweed assemblages along a biogeographical transition zone: inferring potential causes from environmental data. Journal of Biogeography 41, 2293-2306.

Ginovart, M., López, D., and Valls, J., 2002. INDISIM, An Individual-based Discrete Simulation Model to Study Bacterial Cultures. Journal of Theoretical Biology 214, 305-319.

Grimm, V., and Railsback, S.F., 2005. Individual-based Modeling and Ecology. Princeton University Press.

Gropp, W., Lusk, E., Doss, N., and Skjellum, A., 1996. A high-performance, portable implementation of the MPI message passing interface standard. Parallel Computing 22, 789-828.

Grulois, D., Lévêque, L., Viard, F., Frangoudes, K., and Valero, M., 2011. Mosaic genetic structure and sustainable establishment of the invasive kelp Undaria pinnatifida within a bay (Bay of St-Malo, Brittany). CBM-Cahiers de Biologie Marine 52, 485.

Harrison, W.G., Platt, T., and Lewis, M.R., 1985. The Utility of Light-Saturation Models for Estimating Marine Primary Productivity in the Field: A Comparison with Conventional "Simulated" In Situ Methods. Canadian Journal of Fisheries and Aquatic Sciences 42, 864-872.

Hay, C.H., and Luckens, P.A., 1987. The Asian kelp Undaria pinnatifida (Phaeophyta: Laminariales) found in a New Zealand harbour. New Zealand Journal of Botany 25, 329-332.

Higgins, S.I., and Richardson, D.M., 2014. Invasive plants have broader physiological niches. Proceedings of the National Academy of Sciences 111, 10610-10614.

Jassby, A.D., and Platt, T., 1976. Mathematical formulation of the relationship between photosynthesis and light for phytoplankton. Limnology and Oceanography 21, 540547.

Matsumoto, M., and Nishimura, T., 1998. Mersenne twister: a 623-dimensionally equidistributed uniform pseudo-random number generator. ACM Trans. Model. Comput. Simul. 8, 3-30.

McCauley, E., Wilson, W.G., and de Roos, A.M., 1993. Dynamics of Age-Structured and Spatially Structured Predator-Prey Interactions: Individual-Based Models and Population-Level Formulations. The American Naturalist 142, 412-442.

Morita, T., Kurashima, A., and Maegawa, M., 2003a. Temperature requirements for the growth and maturation of the gametophytes of Undaria pinnatifida and $U$. undarioides (Laminariales, Phaeophyceae). Phycological Research 51, 154-160. 
Morita, T., Kurashima, A., and Maegawa, M., 2003b. Temperature requirements for the growth of young sporophytes of Undaria pinnatifida and Undaria undarioides (Laminariales, Phaeophyceae). Phycological Research 51, 266-270.

Murphy, J.T., and Johnson, M.P., 2015. A theoretical analysis of the Allee effect in windpollinated cordgrass plant invasions. Theoretical Population Biology 106, 14-21.

Murphy, J.T., Johnson, M.P., and Viard, F., (submitted). Abundance and recruitment data for Undaria pinnatifida in Brest harbour, France: Model versus field results. Data in Brief.

Ohno, M., and Matsuoka, M., 1993. Undaria cultivation 'wakame'. Seaweed cultivation and marine ranching. Kanagawa International Fisheries Training Center Japan International Cooperative Agency, Yokosuka, 41-49.

Pang, S., and Lüning, K., 2004. Photoperiodic long-day control of sporophyll and hair formation in the brown alga Undaria pinnatifida. Journal of Applied Phycology 16, 83-92.

Parravicini, V., Azzurro, E., Kulbicki, M., and Belmaker, J., 2015. Niche shift can impair the ability to predict invasion risk in the marine realm: an illustration using Mediterranean fish invaders. Ecology Letters 18, 246-253.

Rius, M., Turon, X., Bernardi, G., Volckaert, F.M., and Viard, F., 2015. Marine invasion genetics: from spatio-temporal patterns to evolutionary outcomes. Biological Invasions 17, 869-885.

Saito, Y., 1975. Undaria. Advance of Phycology in Japan, Junk Publishers, The Hague, 304320.

Saulquin, B., Hamdi, A., Gohin, F., Populus, J., Mangin, A., and d'Andon, O.F., 2013. Estimation of the diffuse attenuation coefficient KdPAR using MERIS and application to seabed habitat mapping. Remote Sensing of Environment 128, 224-233.

Schaffelke, B., and Hewitt Chad, L., Impacts of introduced seaweeds, Botanica Marina, Vol. 50. 2007, pp. 397.

Schaffelke, B., Campbell, M.L., and Hewitt, C.L., 2005. Reproductive phenology of the introduced kelp Undaria pinnatifida (Phaeophyceae, Laminariales) in Tasmania, Australia. Phycologia 44, 84-94.

Schaffelke, B., Smith, J.E., and Hewitt, C.L., 2006. Introduced macroalgae - A growing concern. Journal of Applied Phycology 18, 529-541.

Shao-jun, P., and Chao-yuan, W., 1996. Study on gametophyte vegetative growth of Undaria pinnatifida and its applications. Chinese Journal of Oceanology and Limnology 14, 205-210.

Silva, P., Woodfield, R., Cohen, A., Harris, L., and Goddard, J.R., 2002. First Report of the Asian kelp Undaria pinnatifida in the Northeastern Pacific Ocean. Biological Invasions 4, 333-338.

Simberloff, D., Martin, J.-L., Genovesi, P., Maris, V., Wardle, D.A., Aronson, J., Courchamp, F., Galil, B., García-Berthou, E., Pascal, M., Pyšek, P., Sousa, R., Tabacchi, E., and Vilà, M., 2013. Impacts of biological invasions: what's what and the way forward. Trends in Ecology \& Evolution 28, 58-66.

Stevenson, R.D., Peterson, C.R., and Tsuji, J.S., 1985. The thermal dependence of locomotion, tongue flicking, digestion, and oxygen consumption in the wandering garter snake. Physiological Zoology, 46-57.

Suto, S., 1950. Studies on shedding, swimming and fixing of the spores of seaweeds. Bulletin of the Japanese Society of Scientific Fisheries 16, 1-9.

Suto, S., 1952. On shedding of zoospores in some algae of Laminariaceae-2. Bull. Jap. Soc. scient. Fish 18, 1-5. 
615

616

617

618

619

620

621

622

623

624

625

626

627

628

629

630

631

632

633

634

635
Thiébaut, E., Lagadeuc, Y., Olivier, F., Dauvin, J.C., and Retière, C., 1998. Do hydrodynamic factors affect the recruitment of marine invertebrates in a macrotidal area? The case study of Pectinaria koreni (Polychaeta) in the Bay of Seine (English Channel). Hydrobiologia 375-376, 165-176.

Thornber, C.S., Kinlan, B.P., Graham, M.H., and Stachowicz, J.J., 2004. Population ecology of the invasive kelp Undaria pinnatifida in California: environmental and biological controls on demography. Marine Ecology Progress Series 268, 69-80.

Vilà, M., Basnou, C., Pyšek, P., Josefsson, M., Genovesi, P., Gollasch, S., Nentwig, W., Olenin, S., Roques, A., Roy, D., and Hulme, P.E., 2009. How well do we understand the impacts of alien species on ecosystem services? A pan-European, cross-taxa assessment. Frontiers in Ecology and the Environment 8, 135-144.

Voisin, M., Les processus d'invasions biologiques en milieu côtier marin: le cas de l'algue brune Undaria pinnatifida, cultivée et introduite à l'échelle mondiale ( $\mathrm{PhD}$ diss.), Paris 6, France 2007.

Voisin, M., Engel, C.R., and Viard, F., 2005. Differential shuffling of native genetic diversity across introduced regions in a brown alga: Aquaculture vs. maritime traffic effects. Proceedings of the National Academy of Sciences of the United States of America 102, 5432-5437. 


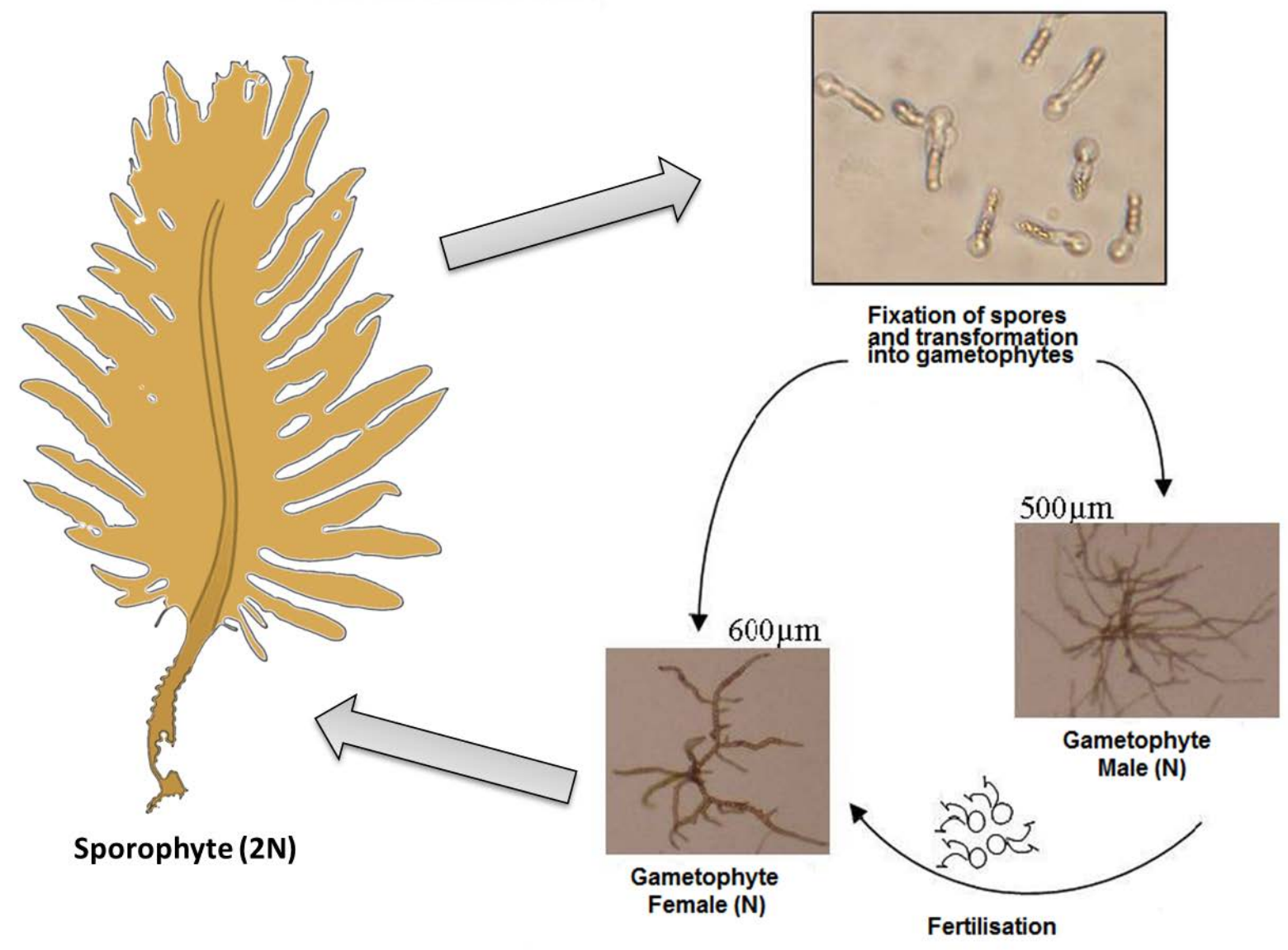

636

637 Fig. 1: Heteromorphic life cycle of Undaria pinnatifida consisting of microscopic haploid

638 (N) gametophyte stages which reproduce sexually to form the diploid (2N) sporophyte stage 639 (1-3 m in length). Photos: Daphné Grulois-Station Biologique Roscoff.

640 
(a)

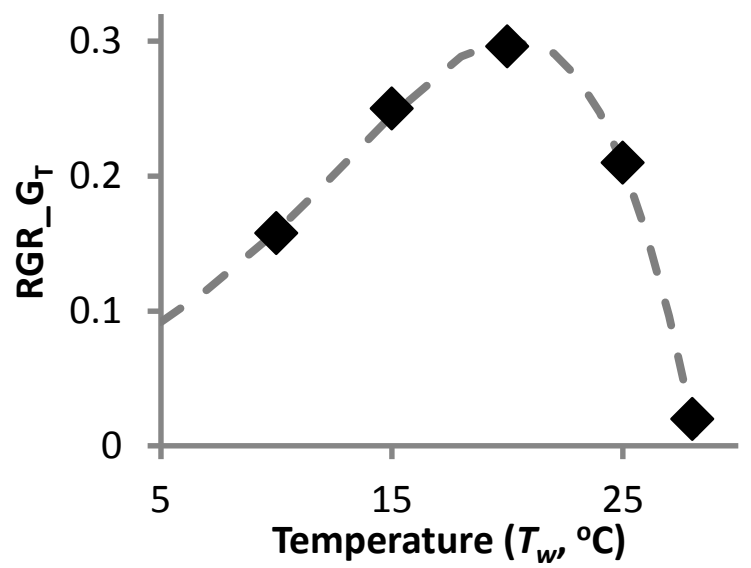

(c)

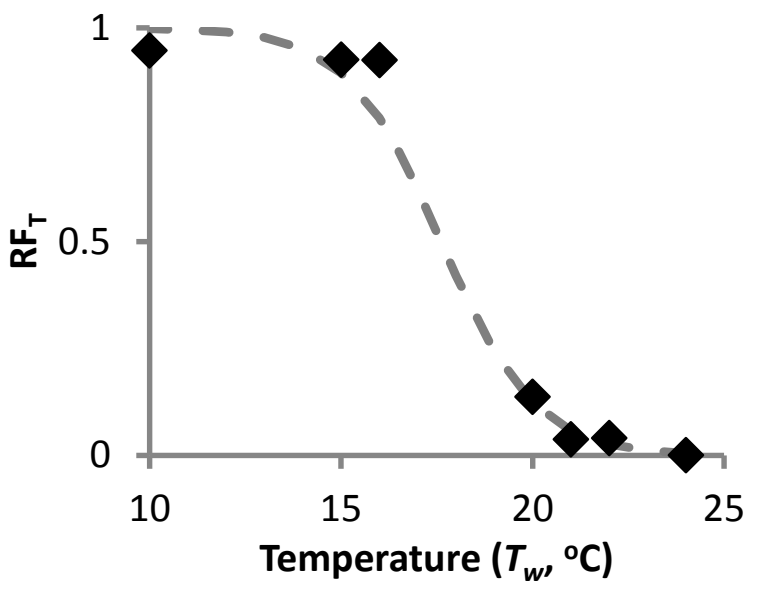

(b) — L:D 8:12 —L:D 12:12 —L:D 16:12

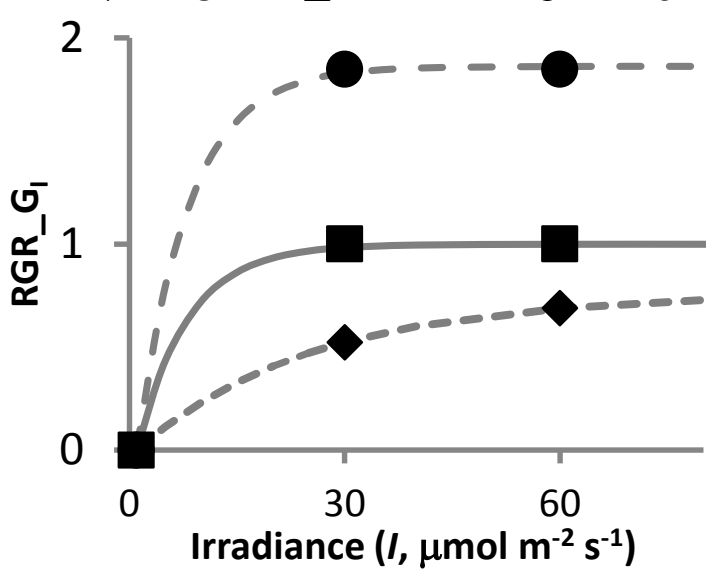

(d)

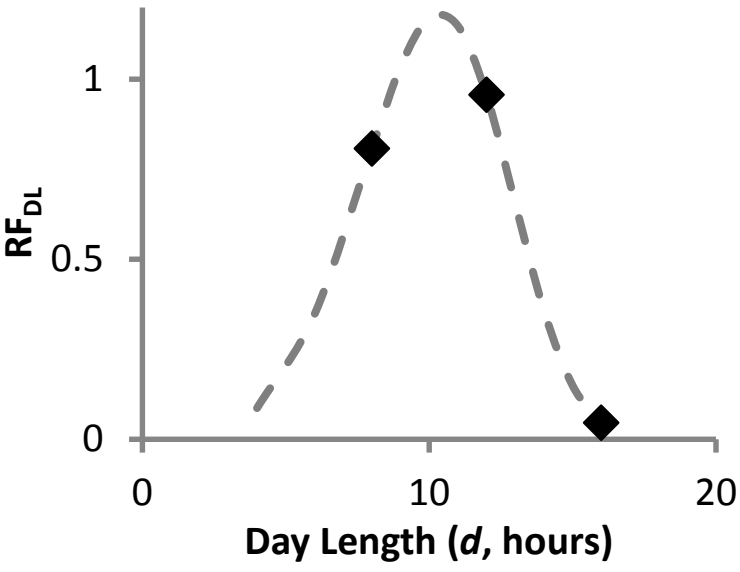

641

642

643 Fig. 2: Response of gametophyte agents to environmental parameters. (a) Relative growth 644 rate in response to temperature $\left(R G R_{-} G_{T}\right)$. Thermal performance curve fitted to data from 645 Morita et al. (2003) $\left(\mathrm{R}^{2}>0.99\right)$. (b) Relative effect of solar irradiance and day length (day 646 light hours) on growth rate (REG_GI): Hyperbolic function fitted to data from Choi et al. 647 (2005) $\left(\mathrm{R}^{2}>0.99\right.$ for all curves). (c) Relative effect of temperature on fertility $\left(R F_{T}\right)$ : Logistic 648 function fitted to data from Morita et al. (2003) and Choi et al. (2005) $\left(\mathrm{R}^{2}=0.97\right)$. (d) Relative 649 effect of day length on fertility $\left(R F_{D L}\right)$ : Weibull distribution fitted to data from Choi et al. $650 \quad(2005)\left(\mathrm{R}^{2}=1.0\right)$. 
(a)

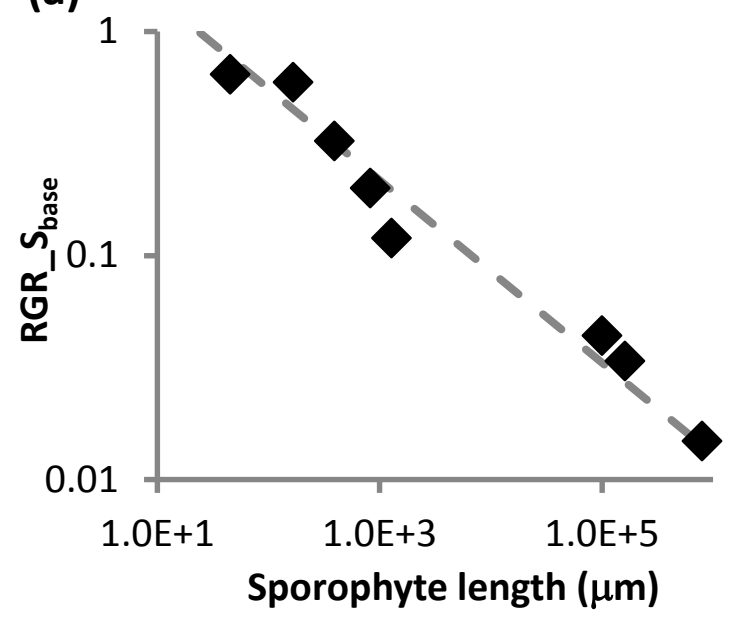

(c)

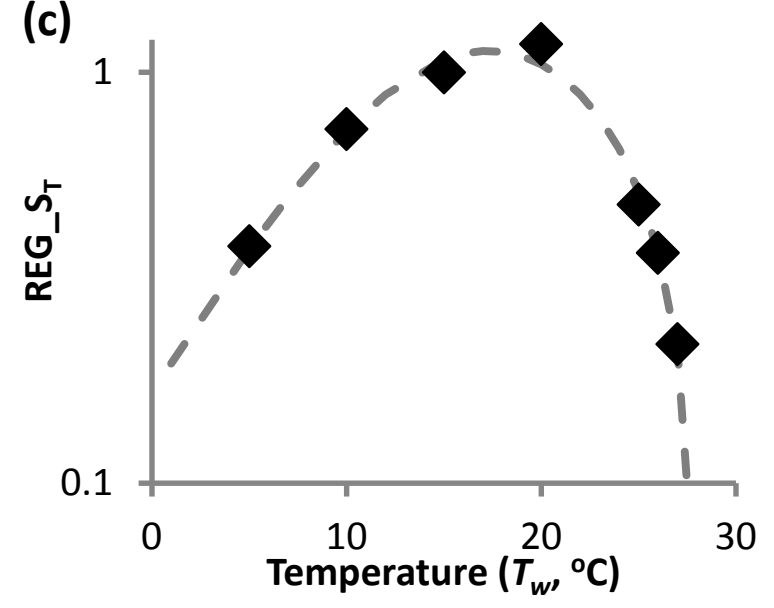

(b)

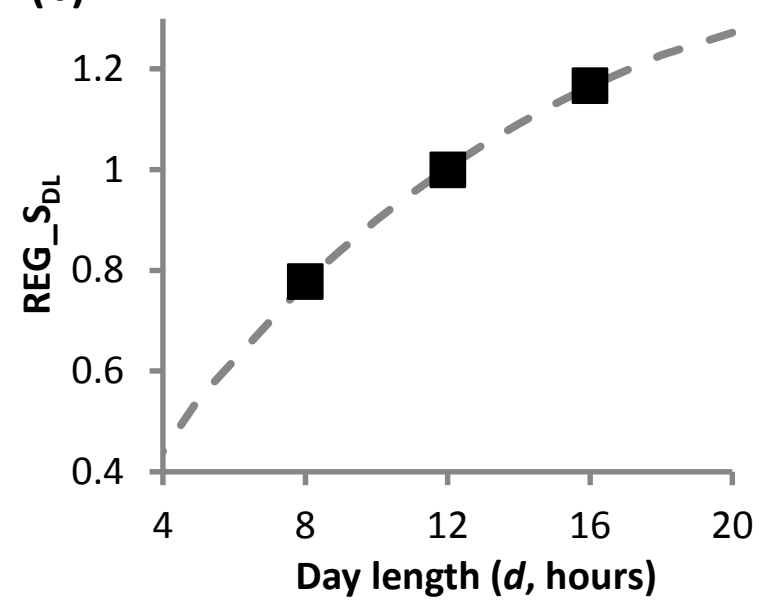

(d)

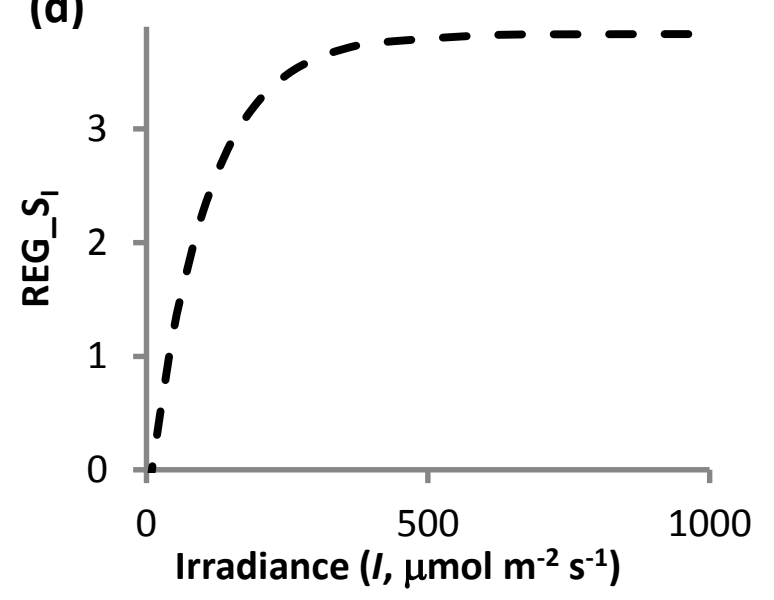

653 Fig. 3: Input data from the literature on the effects of sporophyte length and environmental

654 parameters (day light hours, water temperature and solar irradiance) on the relative growth rate of $U$. pinnatifida sporophytes. (a) Power law relationship $\left(\mathrm{r}^{2}=0.97\right)$ between sporophyte length and relative daily growth rate of sporophytes (RGR_S base) (Pang \& Wu, 1996) (b) Relative effect of changes in day light hours on the growth rate of sporophytes (REG_SDL) 658 (Pang \& Luning, 2004). Hyperbolic equation fitted to data $\left(\mathrm{R}^{2}>0.99\right)$ (c) Relative effect of 659 changes in water temperature on the growth rate (REG_ST) of sporophytes (log scale). 660 Thermal performance fitted to data from Morita et al. (2003) $\left(r^{2}>0.99\right)$. (d) Relative effect of 661 solar irradiance on the growth rate of sporophytes $\left(R E G S_{I}\right)$ based on photosynthesis662 irradiance curve data from Campbell et al. (1999). 


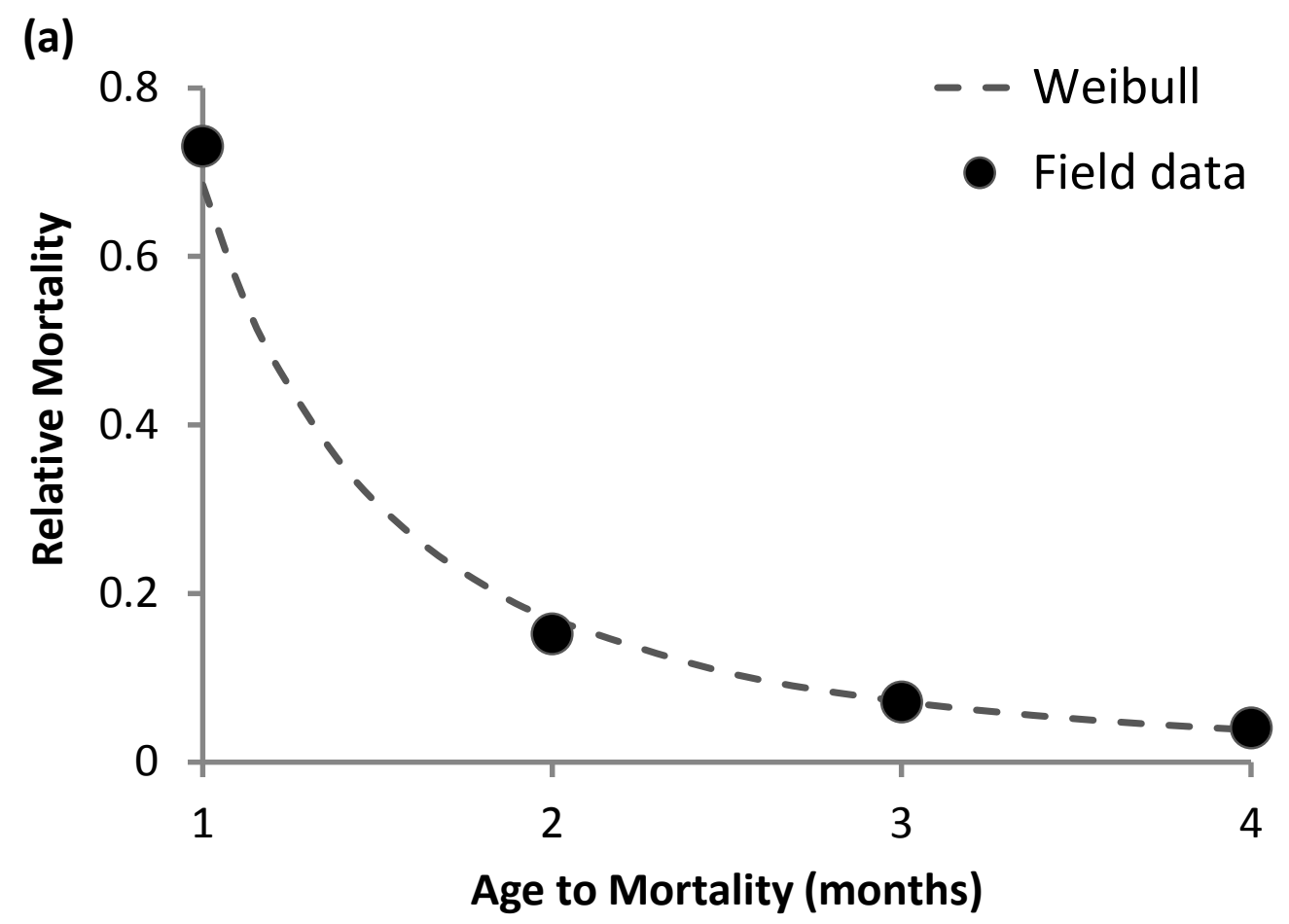

664

(b)

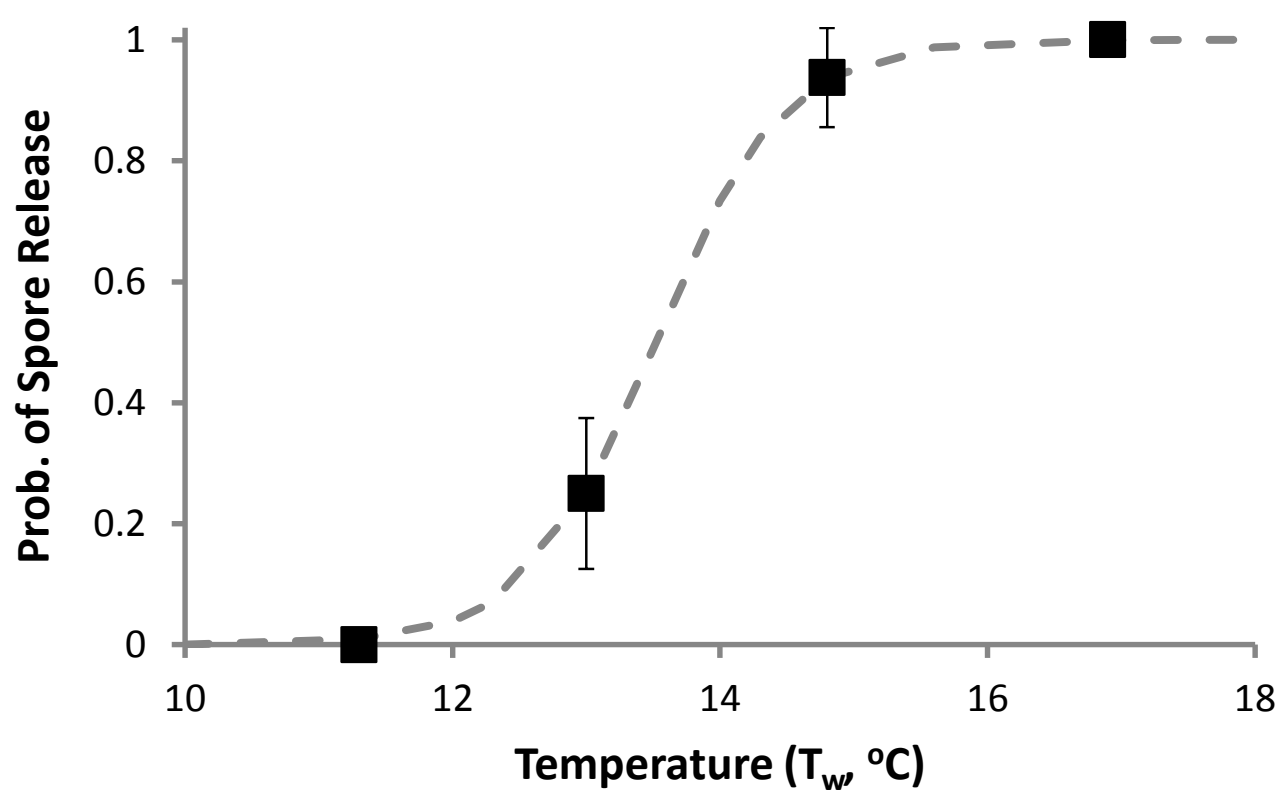

Fig. 4: (a) Field data on the age to mortality of immature sporophytes $(n=198)$ growing in

667 Brest harbour surveyed in the year 2004 (Voisin, 2007). A Weibull distribution ( $k=0.1635$, $668 \lambda=8.2 \mathrm{E}-06)$ was fitted to the data $\left(\mathrm{R}^{2}>0.99\right)$. (b) Impact of water temperature on the 669 probability of spore release from mature U. pinnatifida sporophytes. Logistic function fitted 670 to data from Suto $(1952)\left(\mathrm{R}^{2}>0.99\right)$. 


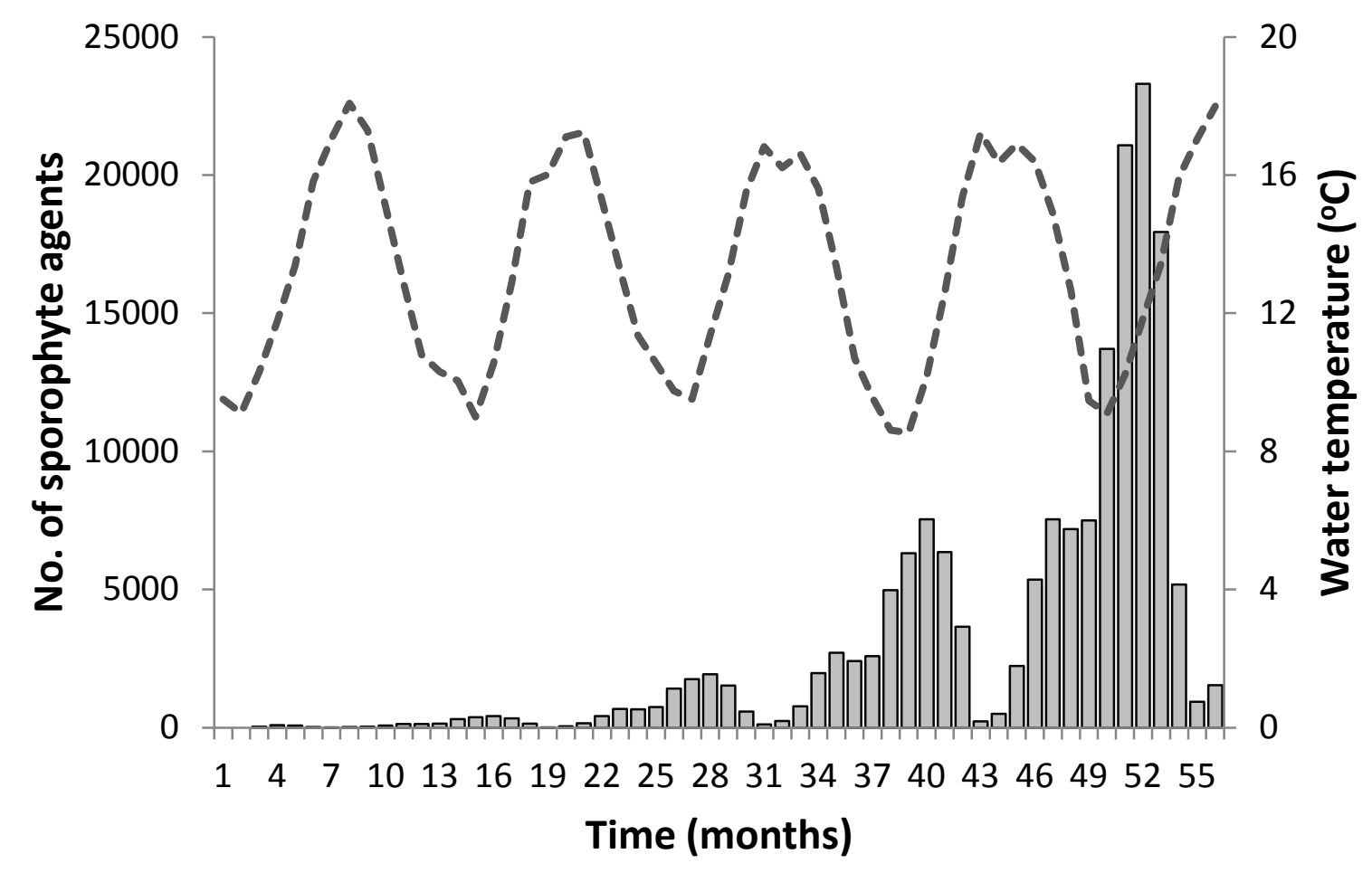

672

673 Fig. 5: Simulation Results: Predicted development of population of $U$. pinnatifida

674 sporophytes over the course of five seasons in environmental conditions representative of

675 Brest harbour, France. Abundance values for sporophytes are plotted on a monthly basis (bar 676 chart). Line chart represents sea water surface temperature input data (SOMLIT, Brest).

677 
(a)

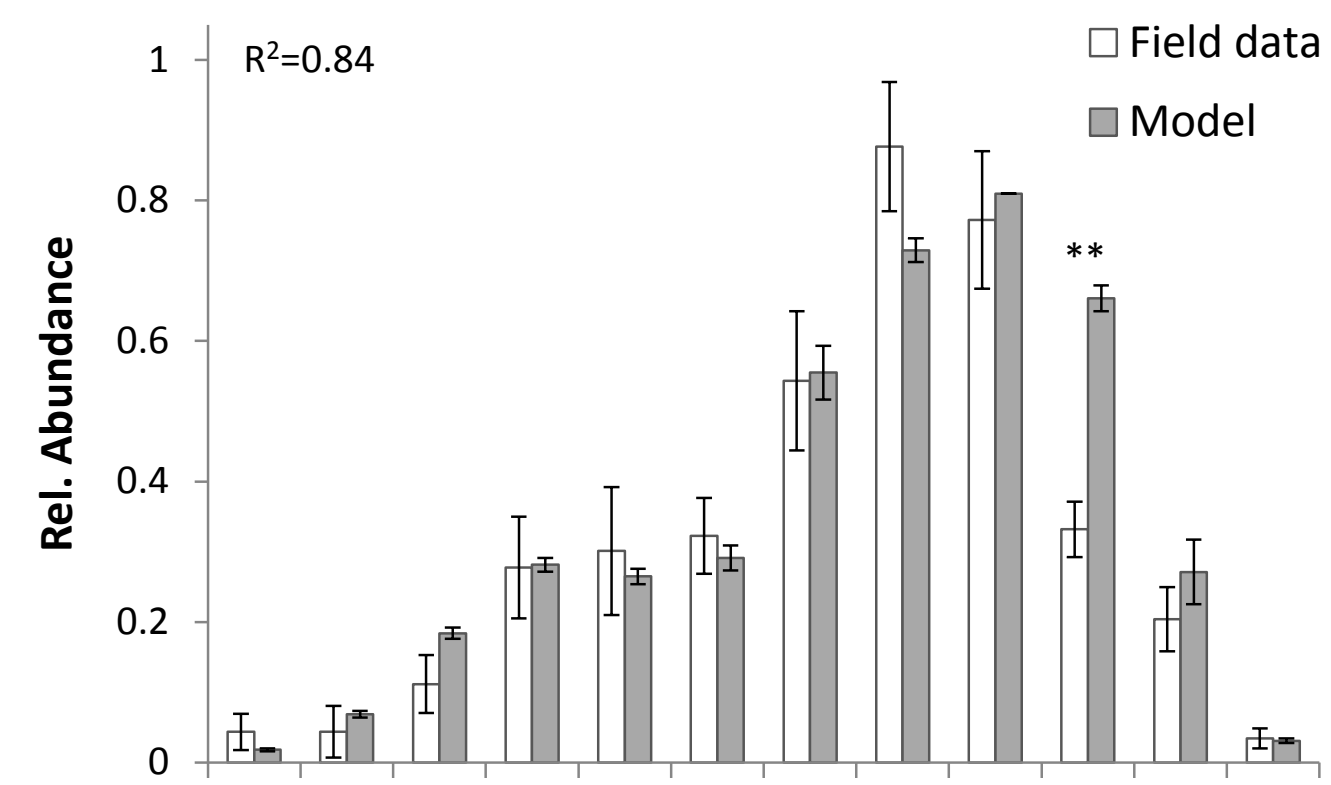

680

Aug Sep Oct Nov Dec Jan Feb Mar Apr May Jun Jul

(b)

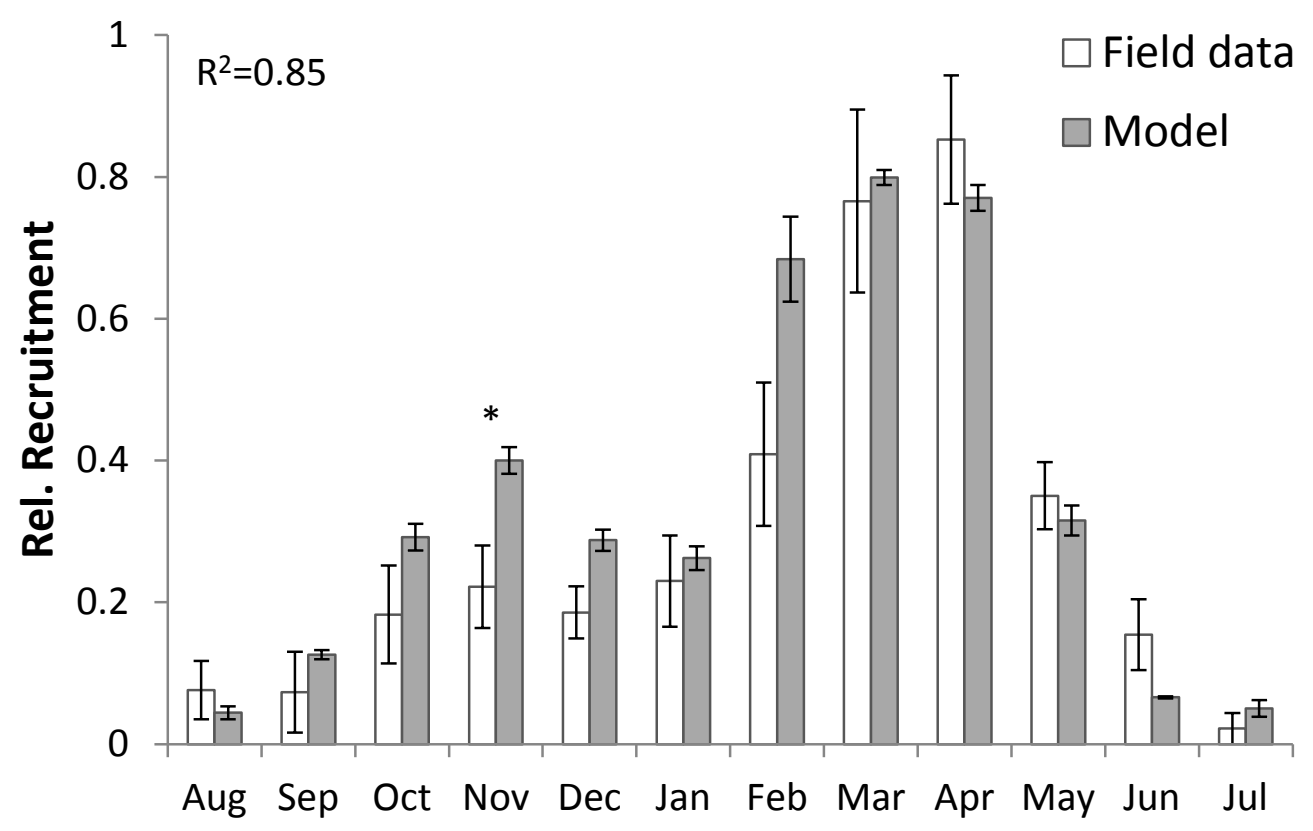

Fig. 6: (a) Predicted relative abundance and (b) relative rate of recruitment of $U$. pinnatifida 684 sporophytes versus field data from a real-world population in Brest harbour, France. Model 685 values are the means $( \pm \mathrm{SE})$ of four simulated years. Field values are the means $( \pm \mathrm{SE})$ from 686 five colour-coded sets of plates, installed in different locations in Brest harbour, for the 687 period Aug 2005 - Jul 2006 (Voisin, 2007). 


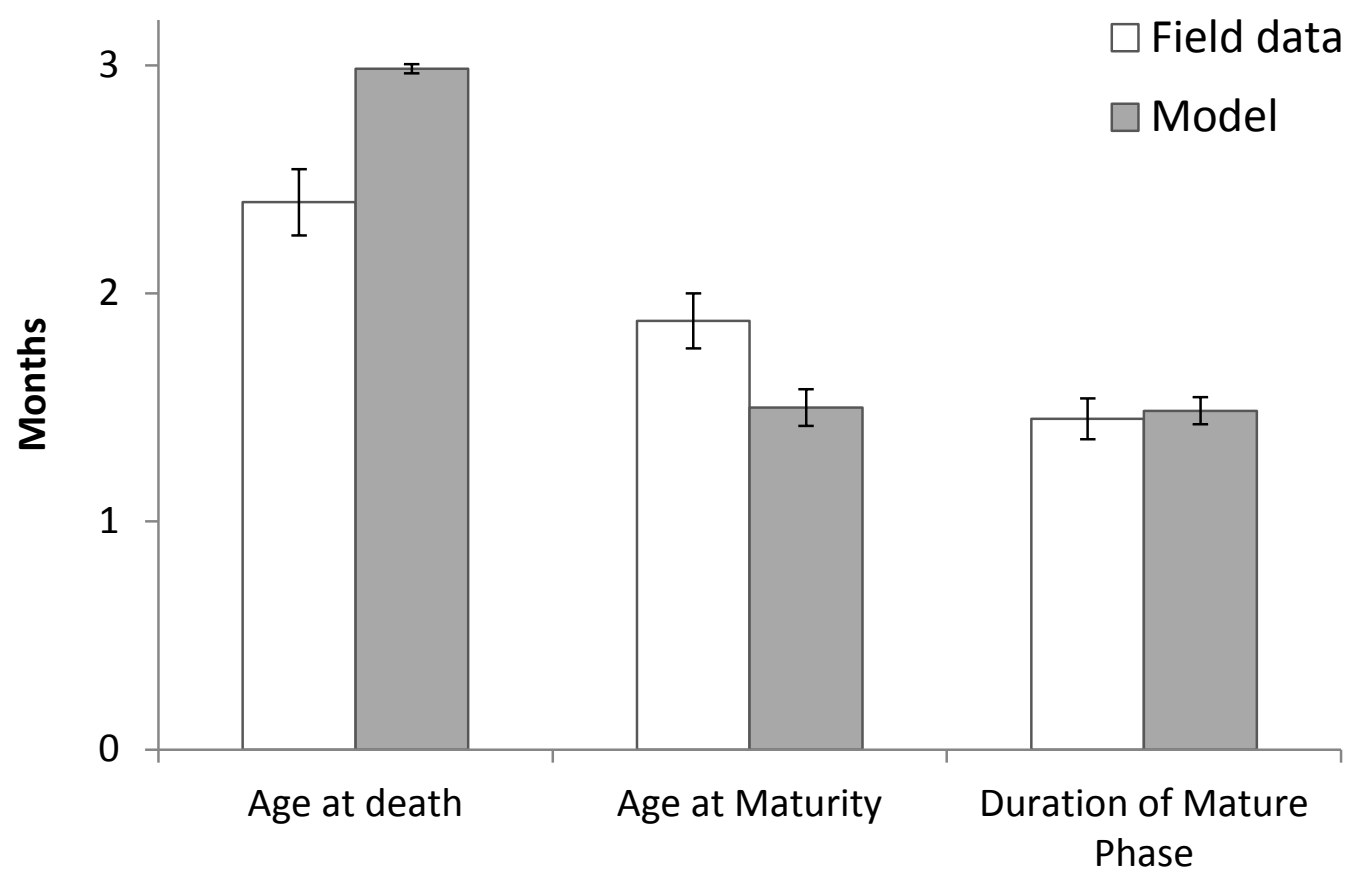

689

690 Fig. 7: Comparison between the predicted life expectancies of mature U. pinnatifida

691 sporophytes and results from field studies of a population sampled $(n=94)$ in Brest harbour

692 over the period 2003-2006 (Voisin, 2007). The mean age at death, mean age at sexual

693 maturity (i.e. formation of sporophylls), and the number of months sexually mature $( \pm \mathrm{SE})$ are

694 compared.

695 


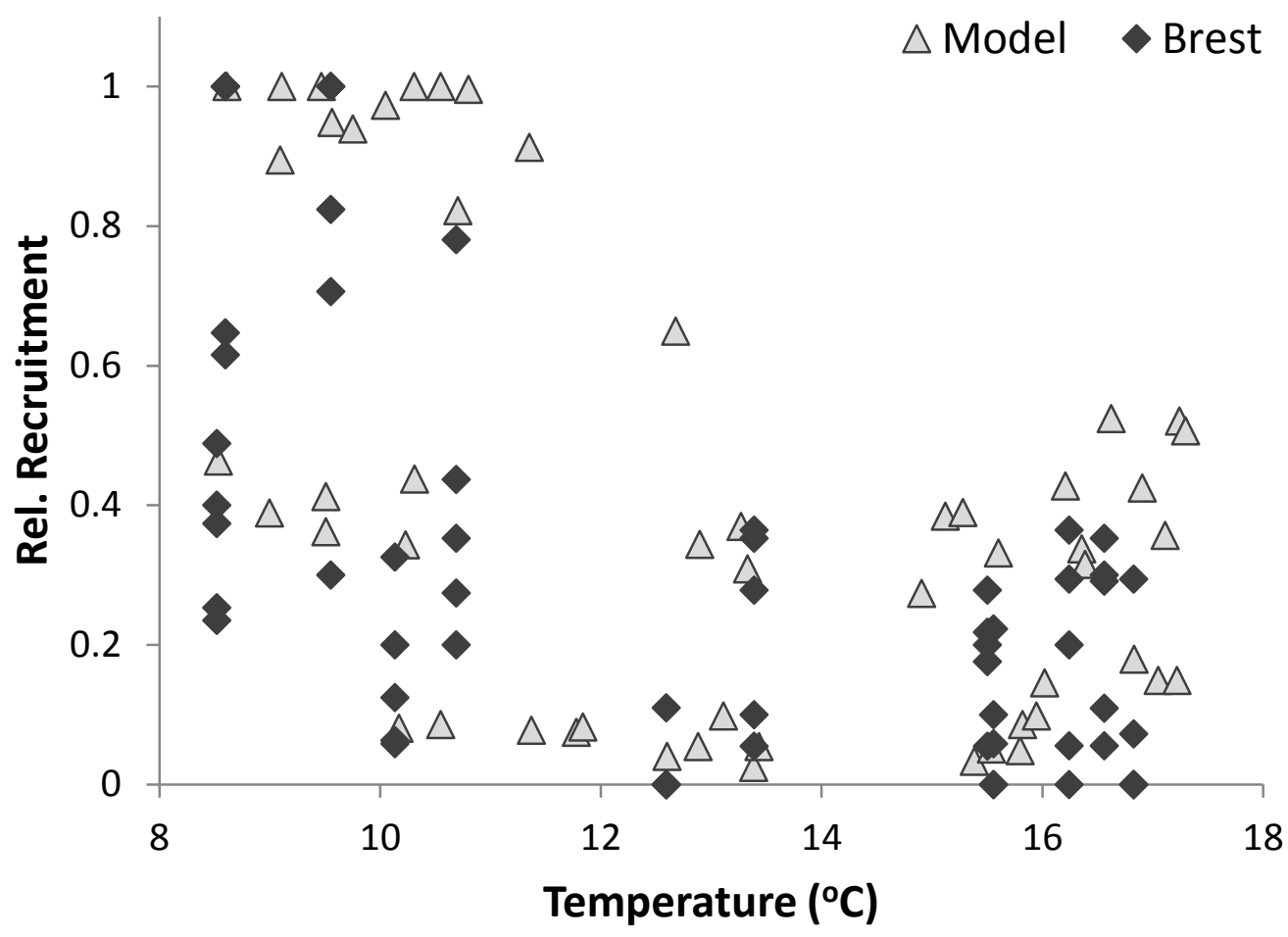

696

697 Fig. 8: Plot of the relationship between recruitment events (appearance of new sporophytes)

698 and water temperature for simulated $U$. pinnatifida populations. Comparison between field

699 data for the years 2003-06 (diamonds) in Brest harbour, France, and model predictions 700 (triangles).

701 
(a)

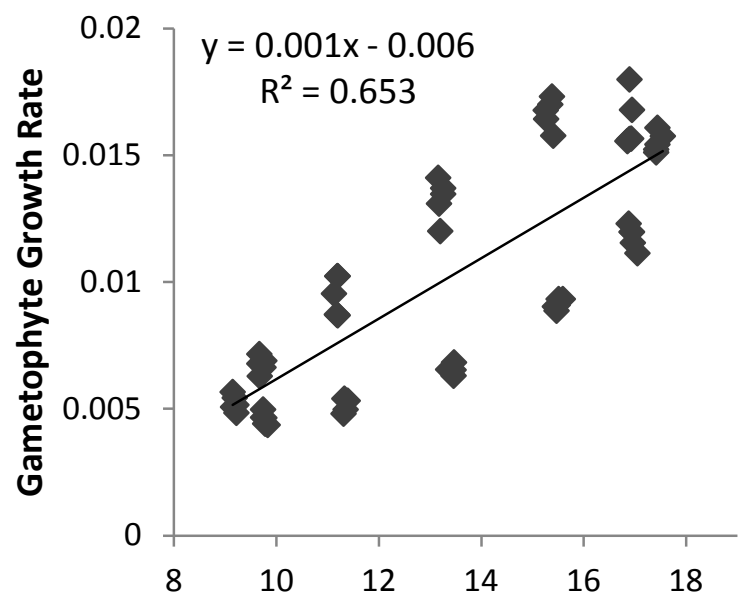

(c)

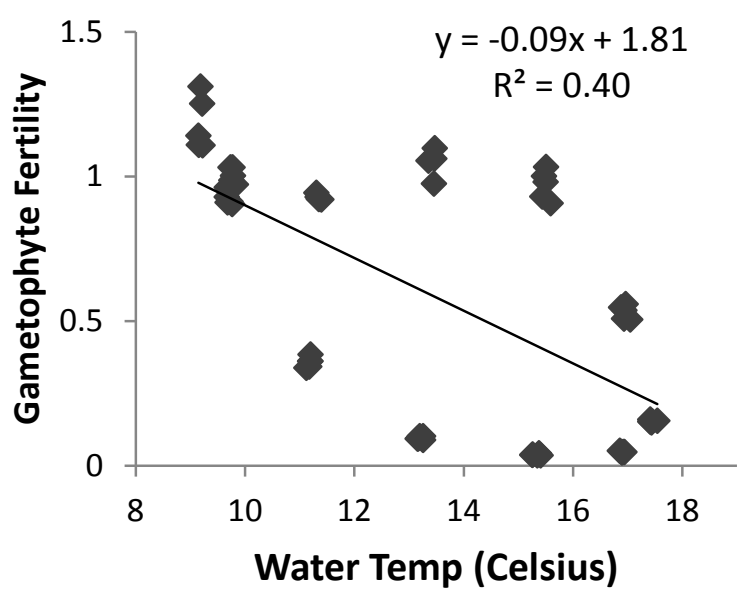

(b)

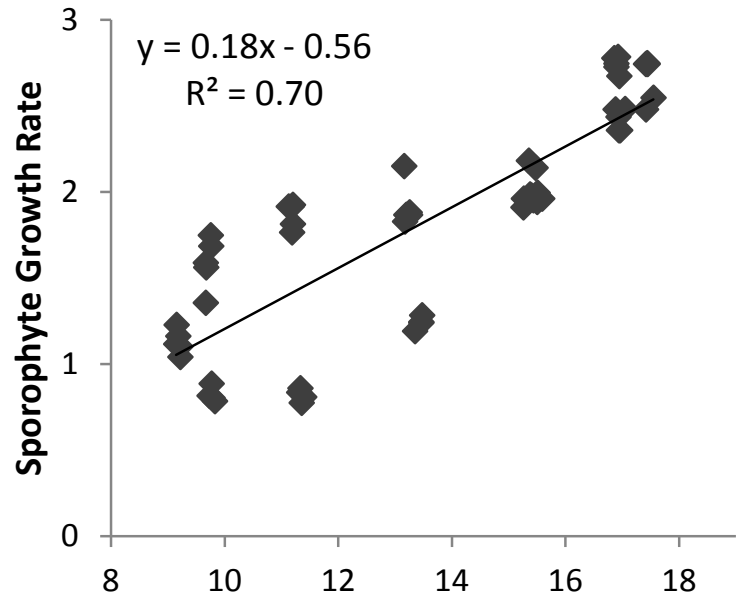

(d)

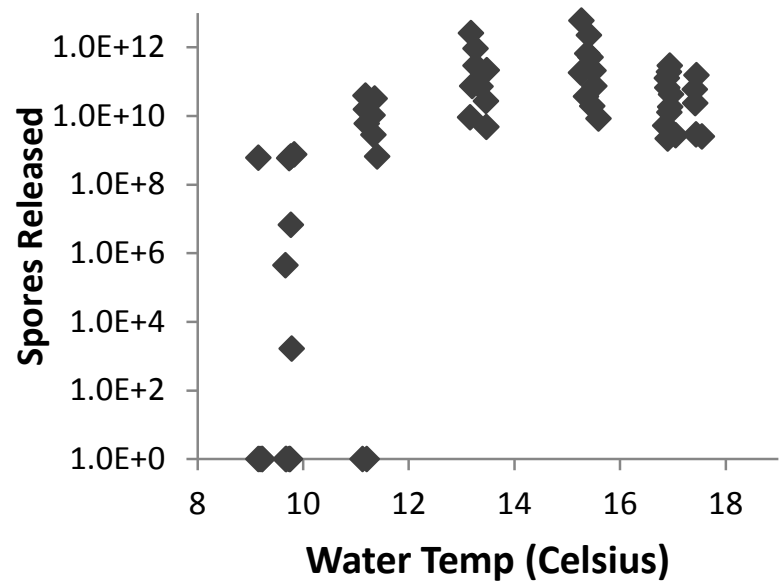

702

703 Fig. 9: Exploration of the effects of temperature on the system dynamics of the model.

704 Relationship between water temperature and: (a) gametophyte growth rate, (b) relative

705 sporophyte growth rate, (c) relative gametophyte fertility, (d) spores released by mature

706 sporophytes (log scale). 
(a)

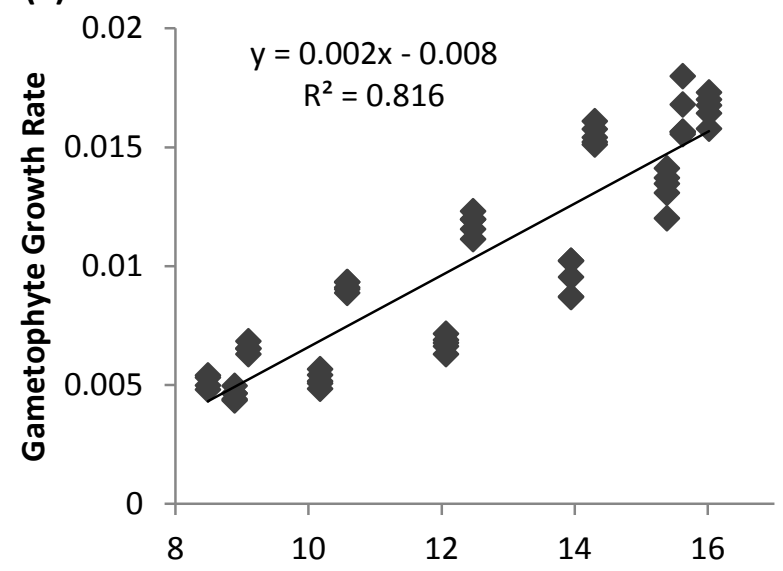

(c)

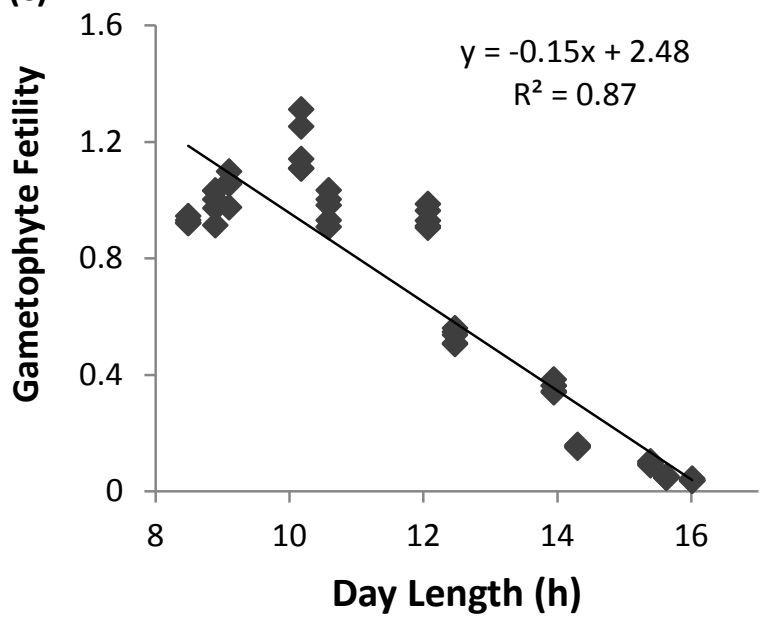

(b)

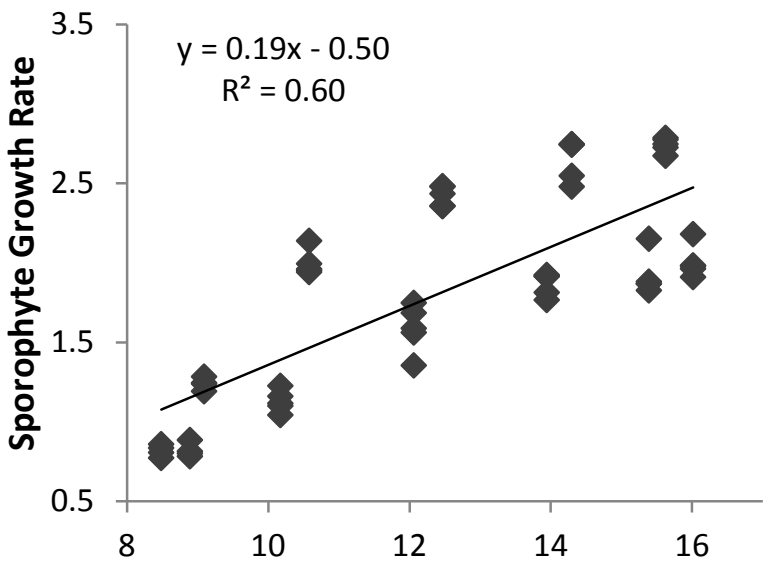

(d)

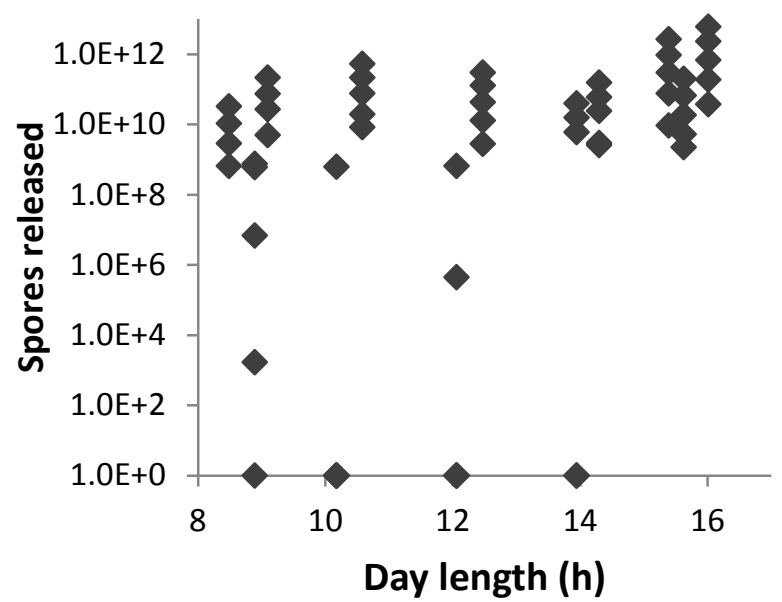

Fig. 10: Exploration of the effects of day light hours on the system dynamics of the model.

710 Relationship between day light hours and: (a) gametophyte growth rate, (b) relative

711 sporophyte growth rate, (c) relative gametophyte fertility, (d) spores released (log scale) by 712 mature sporophytes. 
(a)

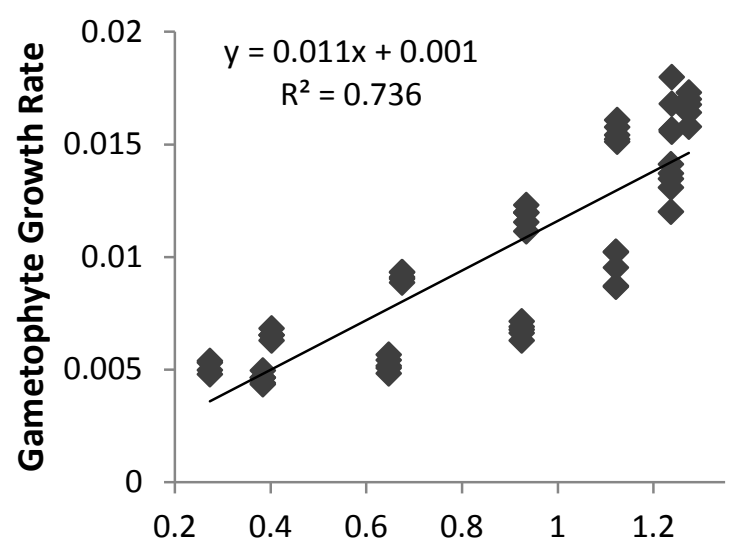

(c)

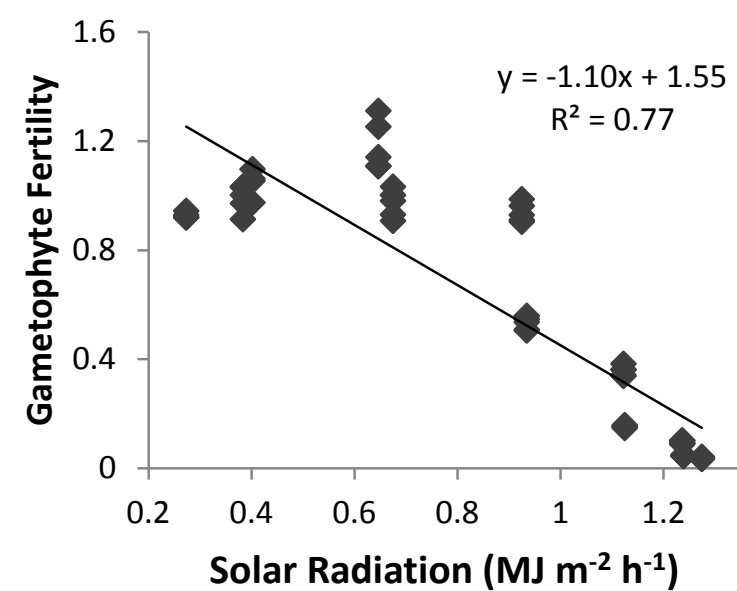

(b)

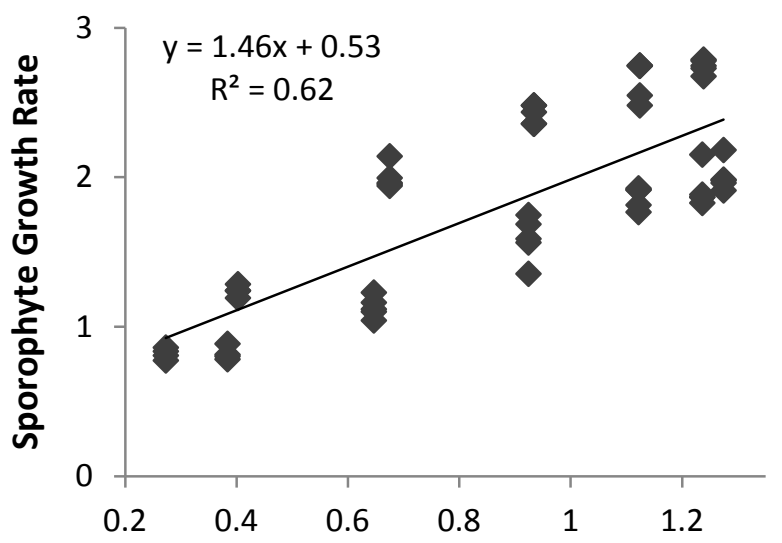

(d)

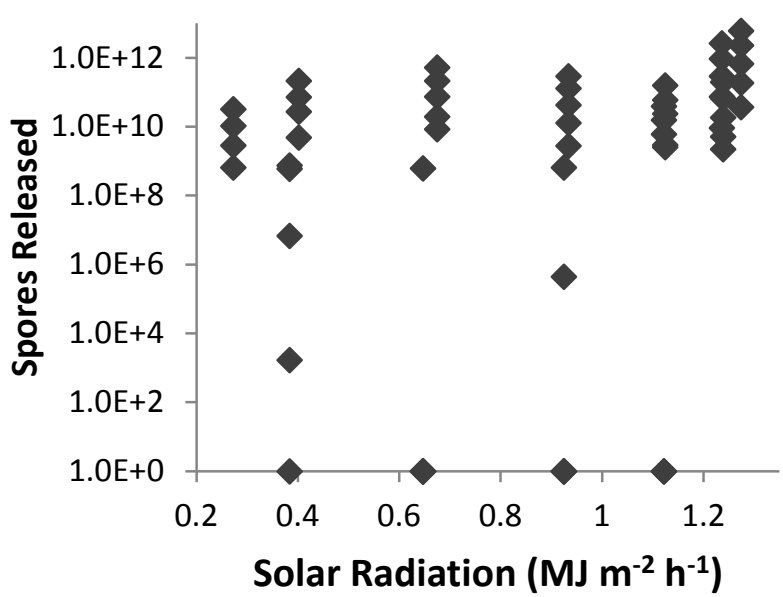

714

715

716

717 718 (log scale) by mature sporophytes.

719

720

Fig. 11: Exploration of the effect of solar radiation (Megajoules $\mathrm{m}^{-2}$ hour $^{-1}$ ) on the system dynamics of the model. Relationship between day light hours and: (a) gametophyte growth rate, (b) relative sporophyte growth rate, $\mathbf{( c )}$ relative gametophyte fertility, (d) spores released 
721 Table 1: Input parameters for CoastGEN simulations of Undaria pinnatifida in 2D simulated

722 coastal environment. $l=$ sporophyte length $(\mu \mathrm{m}), d=$ day light hours, loop = simulation loop.

\begin{tabular}{|c|c|c|}
\hline $\begin{array}{l}\text { Parameter } \\
\text { Type }\end{array}$ & Parameter (units) & Input Value \\
\hline General & $\begin{array}{l}\text { Length of Simulation Loop (hours) } \\
\text { Environment Size (No. of Cells) } \\
\text { Cell Area }\left(\mathrm{m}^{2}\right) \\
\text { Substrate depth in water (m) } \\
\left.\text { Attenuation coefficient (K } \mathrm{K}_{\mathrm{dPAR}}\right)\end{array}$ & $\begin{array}{l}1 \\
514 \times 482 \\
0.25 \\
1.0 \\
0.6\end{array}$ \\
\hline \multirow{6}{*}{$\begin{array}{l}\text { Sporophyte } \\
\text { agents }\end{array}$} & Initial length, $l_{0}(\mu \mathrm{m})$ & 20.0 \\
\hline & Base growth rate & $3.615 l^{-0.407}$ \\
\hline & $\begin{array}{l}\text { Day length response (hyperbolic curve): } \\
P_{\max } \\
a \\
I_{c}\end{array}$ & $\begin{array}{l}1.56 \\
0.13 \\
0.0\end{array}$ \\
\hline & $\begin{array}{l}\text { Thermal performance curve : } \\
K_{1} \\
K_{2} \\
K_{3} \\
C T_{\min } \\
C T_{\max } \\
\text { Scale }\end{array}$ & $\begin{array}{l}21.09 \\
0.213 \\
0.006 \\
1.62 \\
28.28 \\
3031\end{array}$ \\
\hline & $\begin{array}{l}\text { Photosynthesis-irradiance curve: } \\
P_{\max } \\
a \\
I_{c}\end{array}$ & $\begin{array}{l}0.4 \ln (l)-0.596 \\
0.5 l^{-0.33} \\
2.5 \ln (l)-19.9\end{array}$ \\
\hline & Mean length at maturity (cm) & 32.66 \\
\hline $\begin{array}{l}\text { Gametophyte } \\
\text { agents }\end{array}$ & $\begin{array}{l}\text { Thermal performance curve : } \\
K_{1} \\
K_{2} \\
K_{3} \\
C T_{\min } \\
C T_{\max } \\
\text { Scale }\end{array}$ & $\begin{array}{l}35.67 \\
0.158 \\
0.015 \\
4.45 \\
28.24 \\
10.63\end{array}$ \\
\hline
\end{tabular}




\begin{tabular}{|c|c|c|}
\hline & $\begin{array}{l}\text { Photosynthesis-irradiance curve: } \\
P_{\max } \\
a \\
I_{c}\end{array}$ & $\begin{array}{l}0.29 e^{0.11 d} \\
0.029 d-0.2 \\
0.0\end{array}$ \\
\hline & Prob. of fertilisation $\left(\right.$ loop $\left.^{-1}\right)$ & 0.0002 \\
\hline Gametogenesis & $\begin{array}{l}\text { Temperature response curve (log): } \\
\mathrm{x}_{0} \\
\mathrm{k}\end{array}$ & $\begin{array}{l}17.6 \\
0.82\end{array}$ \\
\hline & $\begin{array}{l}\text { Day length response (Weibull): } \\
\alpha \\
\beta\end{array}$ & $\begin{array}{l}4.5 \\
10.96\end{array}$ \\
\hline Spores & $\begin{array}{l}\text { Half-life (hours) } \\
\text { Release rate }\left(\text { agent }^{-1} \text { loop }^{-1} \text { ) }\right. \\
\text { Spore stock }\left(\text { agent }^{-1} \text { ) }\right. \\
\text { Diffusion coefficient } \\
\text { Prob. of germination }\left(\text { loop }^{-1} \text { ) }\right.\end{array}$ & $\begin{array}{l}24 \\
2.0 \times 10^{7} \\
10^{10} \\
0.15 \\
10^{-9}\end{array}$ \\
\hline
\end{tabular}

